\title{
A Focus Group Study of Diverse Local Populations and Their Health Care Experiences in Northeastern Pennsylvania: Cross-Cultural Issues
}

\author{
Linda Trompetter ${ }^{1}$, Arthur Breese ${ }^{1}$, James Calderone ${ }^{1}$, Grace S. Fisher ${ }^{1}$, Rodrigo Gereda ${ }^{2}$, Mari \\ King ${ }^{1}$, Richard Kramer ${ }^{3}$, Anne Lin ${ }^{4}$, Hisham A. Nabaa4, Lalit Shah ${ }^{1}$, Theresa Tyler Smith ${ }^{5}$, \\ Mayon Sylvain ${ }^{6}$, Suzy Weinman ${ }^{3}$ \\ ${ }^{1}$ College Misericordia \\ ${ }^{2}$ Peace Center \\ ${ }^{3}$ Jewish Family Service of Greater Wilkes-Barre \\ ${ }^{4}$ Wilkes University \\ ${ }^{5}$ American Red Cross \\ ${ }^{6}$ Sisters of Mercy
}

\begin{abstract}
This investigation was conducted through the support of the College Misericordia Diversity Institute and a grant from the Blue Ribbon Foundation of Blue Cross of Northeastern Pennsylvania. Focus group participants were 49 adults from seven minority populations residing in northeastern Pennsylvania's Luzerne and Lackawanna counties. Data was collected by 11 focus group leaders who were members of a Blue Ribbon Grant Core Committee at College Misericordia in 2004. The seven populations studied were African Americans, Arabic Muslims, Asian-Chinese and Korean, Gay and Lesbian, Hispanic, Jewish, and Asian Indian. A 30-question survey was used to collect data during one to two hour focus group interviews. Through content analysis, six problematic issues faced by many of the participants were identified. All of the findings were validated by a review process. The six issues faced by the 7 groups were: 1) Economics, Education, and Employment Influence Life for Newcomers, 2) Customs and Traditions Sometimes Sacrificed- The Influence of American Culture, 3) Socialization Often Limited to Same Population Group, 4) Mixed Acceptance Level from Area Natives, 5) Bilingual Challenges Impede Optimal Inclusion, 6) Health Care Access Problems. The aforementioned cross-groups study is explored in this report. The study also yielded seven other reports (one for each diverse population) which provide a description of that particular focus group's perspective on topics such as religion, food, family, customs, and health care (see Appendices $\underline{A}, \underline{B}, \underline{C}, \underline{D}, \underline{E}, \underline{F}$, and $\underline{G}$ ). Findings of this study are being disseminated in a local effort to educate health care professionals. Future research will be needed to determine if progress is being made in fulfilling the health care needs of all diverse populations living in Luzerne and Lackawanna County, as well as other parts of northeastern Pennsylvania.
\end{abstract}

(C)2005 Californian Journal of Health Promotion. All rights reserved.

Keywords: ethical, racial, and religious differences, health care, health care access

Wakefield (2003) said cultural diversity is a major challenge to the ever-changing U.S. health care system. She highlighted the need for health care policy makers to encourage health care providers to work toward resolving problems with minority access to health care services. In response to calls such as Wakefield's, our study sought to show how a group of health care professionals and educators, with the support of a local health care foundation, sought to understand the problem of health care access in their region and begin to solve health care equity problems.

Ethnic, racial, and religious differences continue to evolve in the populations of northeastern Pennsylvania. Historically, the region attracted large numbers of immigrants seeking opportunity and change. The earliest of these opportunities were jobs in the coal mining 
industry, which brought large numbers of eastern European immigrants to the region in the late 1800's and early 1900's. Over the past century a small but steady number of African Americans from Philadelphia and more southern U.S. cities also chose to settle in this region. Immigration to the area continues to this day, as individuals from Hispanic, Asian, Asian Indian, and other backgrounds are attracted here by economic opportunities. The population of northeastern Pennsylvania continues to become more diverse in terms of its cultural characteristics.

Communication barriers, religious differences, and variations in traditions and customs make it difficult to meet the health care needs of the diverse groups now living in northeastern Pennsylvania. The vast majority of this region's health care providers are not members of minority populations. Lack of familiarity with the customs of diverse populations impedes the delivery of health care services. With these challenges in mind, College Misericordia and its Diversity Institute were the recipients of a grant from the Blue Ribbon Foundation of Blue Cross of Northeastern Pennsylvania. This investigation was conducted under the auspices of that grant.

This focus group study sought to obtain information to assist local health care providers in serving individuals who are diverse in areas such as culture, race, ethnicity, and language. One purpose of this focus group study was to learn about the beliefs, values, and customs of under-served populations living in the area. A second purpose was to obtain information about the health care practices and local health care system experiences of members of these groups. Ultimately, the grant program of which this study is a part sought to contribute to the development of an inclusive health care system which optimally serves all individuals residing in the region. Therefore, the results of this study are now being communicated to local health care providers by an educational program offered by the Diversity Institute of College Misericordia, with support from the Blue Cross Blue Ribbon Foundation.

\section{Method}

Approval for the study was granted by the Institutional Review Board at College Misericordia in Dallas, Pennsylvania. Participants were 49 adults from the seven minority populations targeted in the study. They were recruited for participation by 11 focus group leaders. These 11 leaders were qualified health care and human service professionals from a variety of disciplines. They were members of a Blue Ribbon Grant Core Committee which met monthly at College Misericordia for a one year period from September 2004 through May 2004. They planned and reviewed the progress of the Blue Ribbon Grant activities which included this study. Time was dedicated at the monthly meetings for planning and information dissemination concerning this research study.

Focus groups were established for each of seven diverse population groups. Some groups had one focus group leader, while others had two. At least one of each of the focus group leaders was of the same cultural background as the members of their focus group. Table 1 shows the number of participants in each of the focus groups, and illustrates their ethnic diversity.

Training for the focus group leaders occurred in February 2004. It included a 2 hour workshop on data collection which provided information on the use of the study's data collection tools and interviewing techniques. At the workshop, focus group leaders learned how to obtain informed consent, collect demographic information, and use of the focus group survey. Participants who did not attend the training session viewed the training materials via a Powerpoint presentation. Additional instruction on completion of the researcher summary was provided at one of the monthly meetings. 
Table 1

Minority Focus Groups

\begin{tabular}{|l|c|}
\hline Population Represented & Number of Focus Group Participants \\
\hline African American & 7 \\
\hline Arabic Muslims & 3 \\
\hline Asian-Chinese and Korean & 6 \\
\hline Asian-Indian & 8 \\
\hline Gay and Lesbian & 5 \\
\hline Hispanic & 13 \\
\hline Jewish & 7 \\
\hline Total & 49 \\
\hline
\end{tabular}

The study's data collection tools included a 30question survey which participants completed prior to the focus group meeting. Additionally, each focus group leader completed demographic and summary sheets concerning group participants and proceedings. Data collection for the focus group study occurred between March and August of 2004. The focus group leaders first distributed a survey form to each participant with instructions to complete it. Focus group leaders then reviewed the completed survey forms prior to the focus group meetings. The leaders used this information to probe for clarification and additional information during the focus group interview sessions. The survey data collection process required one to two hours of time from each participant. Interviews were conducted with participants either in a group session or individually, depending on their preference. For example, some focus groups were conducted in one session with all participants present. Other focus group participants completed surveys in writing and were then interviewed individually in one session.

The results of the study are presented in two formats in this report: (a) a discussion of the six common problematic issues which occurred across all of the diverse populations, and (b) population-specific findings which are presented in the appendices. All of the findings were validated by a review process. Three of the authors of this report (who were all members of the grant committee and also served as focus group leaders) verified the survey content analysis which resulted in the population- specific findings found in the appendices. They also reviewed and validated the common issues which emanated across all population groups. All members of the research team were presented with the findings and asked to give feedback, as part of the development of this report.

\section{Results}

\section{Population- Specific Findings}

The population-specific findings for each of the seven groups are presented in Appendices A (African American), $\underline{B}$ (Arabic Muslims), $\underline{\mathrm{C}}$ (Asian- Chinese and Korean), $\underline{\mathrm{D}}$ (Gay and Lesbian), E (Hispanic Americans), F (Jewish Population), and $\underline{G}$ (Asian Indian Americans). The development of these reports began with the focus group leader- who wrote a researcher summary for his/her group based on the interview data. One of the researchers (who had experience in qualitative research) then compiled and edited these final descriptive reports. Each population-specific summary describes that particular focus group's perspective on topics such as religion, food, family, customs, and health care.

\section{Common Issues Across the Seven Diverse Populations.}

The aforementioned qualitative researcher then performed a content analysis to determine common problematic issues faced by the Seven diverse cultural groups. These issues were identified by systematically examining all of the study data, and by noting areas which were seen as problematic or challenging by the majority of the study participants across all seven of the 
cultural groups. An issue was seen as problematic or challenging if it was frequently voiced by numerous participants from several cultures, or if it was emphatically stated or emotionally described by a majority of the participants. These common issues are presented in Figure 1, and are described below.

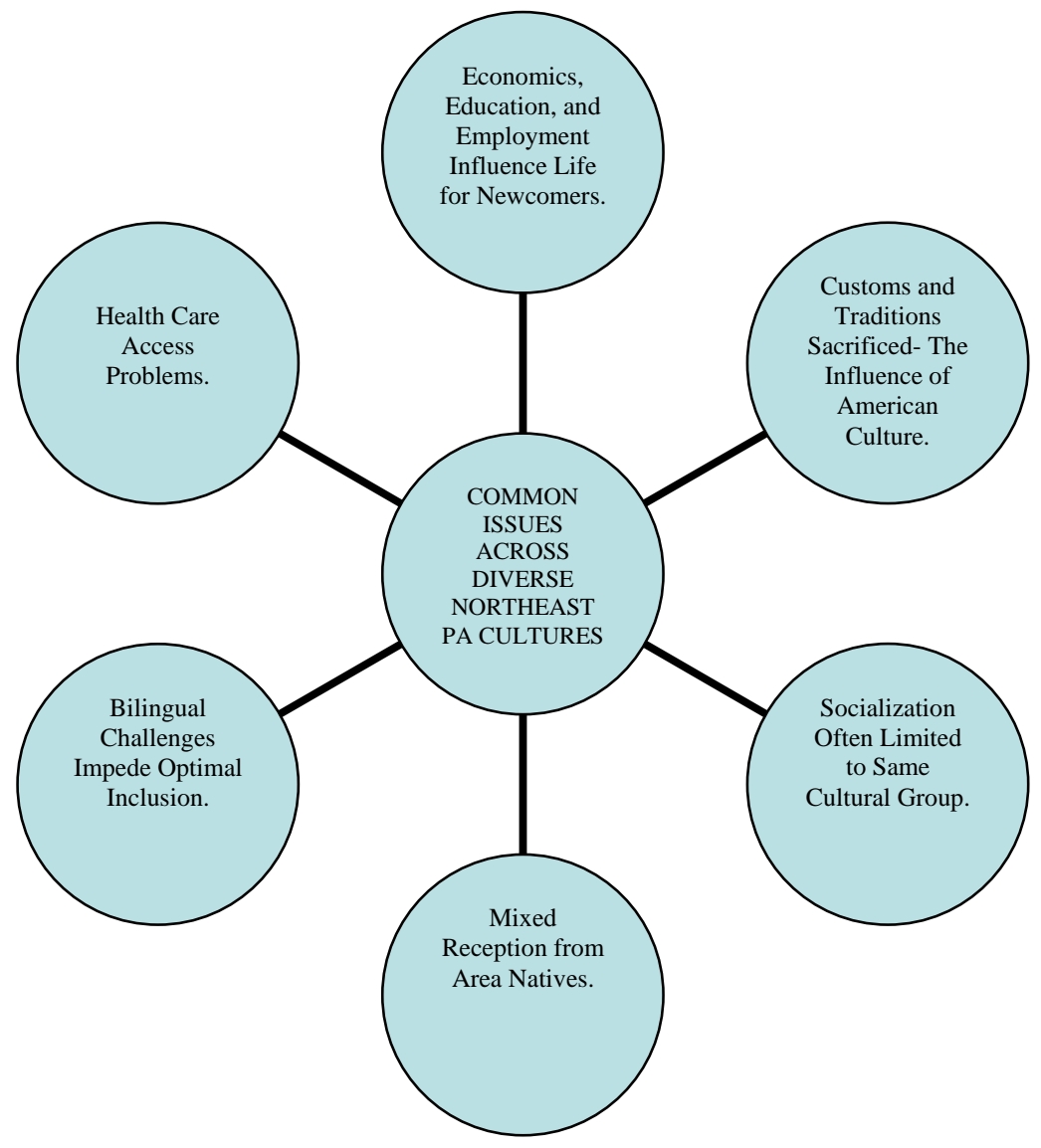

Figure 1

Common Issues Across the Seven Diverse Populations

Problematic Issues

Economics, Education, and Employment Influence Life for Newcomers. Many of the participants described their reasons for relocating to the Luzerne and Lackawanna County area. Educational and employment opportunities were often given as their impetus for moving to the region. Employment opportunities included professional opportunities for physicians from the Asian Indian American group and teaching opportunities for educated Chinese American residents of the area. Non- professional jobs attracted members of the groups as well, such as Chinese American restaurant workers and Hispanic factory employees. Some Arabic Muslims came here for positions in higher education.

Economic factors, and the fact the area was perceived as a good place to raise children, were influential in attracting African Americans to this area. All of the participants from the African American group had moved here from the south, looking for better lives free from discrimination. 
Family connections were another attraction to the area, particularly for the Hispanic participants. Many of them made the decision to move here based on positive recommendations from relatives or friends already living in the region. Educational level was seen by the focus group leaders as a factor which greatly influenced success and adaptation to life in northeastern Pennsylvania. For example, newcomers and immigrants with higher education tended to obtain higher paying jobs here, while those with limited education often ended up with lower paying jobs. Those with higher incomes were more satisfied with their access to health care, too. Individuals with limited financial resources tended to be less satisfied with the health care system. They also tended to rely on free clinics for these services.

\section{Customs and Traditions Sometimes} Sacrificed- The Influence of American Culture. Many of the participants described a strong dedication to the specific religious and cultural traditions of their culture. These included Jewish participants who revealed special customs related to marriage; Chinese American participants who described special beliefs about food and healing; and Asian Indian Americans who detailed numerous holiday customs and traditions.

The influence of religion was exceptionally strong in the findings from the Arabic Muslim focus group. One of the participants of that focus group quoted numerous verses from the Qur'an to illustrate his answers on the survey form. His answers were detailed, thoughtful, and written with much intensity.

One of the African Americans mentioned it was important in that culture for individuals to be addressed as "Mr." or "Mrs." This person expressed concern about the fading of this tradition. He noted this tradition is also not supported by recent health care confidentiality requirements, which compel patients to be called only by their first names when summoned from medical waiting areas.

Each of the minority groups had their own distinct set of customs. However, there was one common trend seen in many of the groups as it relates to these traditions. Many said these practices often seem to be fading in the shadow of the influence of American culture. In spite of this trend toward blending with the predominant culture, the participants still expressed much pride and fondness for these unique aspects of their background.

Socialization Often Limited to Same Population Group. Varying degrees of integration into the broader social group were seen across the minority populations. The Jewish participants seemed to voice much confidence in their inclusion in broader American society. The Arabic Muslims also indicated significant involvement in various aspects of the larger society, but at the same time noted the importance of seeing other members of their group. The mosque, in particular, was a place where this occurred.

The Asian Indian Americans voiced some degree of integration, but also indicated strong social bonds to members of their same cultural group. The Chinese, Korean, and Hispanic groups demonstrated great reliance on members of their same population group for meeting social needs. Similarly, the African American participants expressed a tendency to socialize with other African Americans in organizations such as church, the National Association for the Advancement of Colored People (NAACP), and the Order of the Eastern Star.

Mixed Acceptance Level from Area Natives. Overall, the participants experienced mixed attitudes from local residents toward minorities. They described both positive and negative receptions from natives of the area. Some participants were very quick to say they felt welcomed by local inhabitants. Although the Arabic Muslim participants noted no overt problems with lack of acceptance by the natives, they did say some of the natives lack cultural understanding. Others said they were not received positively, and described being subjected to prejudicial remarks and even hatred. One Asian participant described an experience involving hurtful remarks from a native of the area. 
Community acceptance was a particularly relevant concern for the gay and lesbian participants. Their issues included the need to be vigilant about their own, their children's, and their partners' physical and emotional safety; the need to feel welcomed, included, and respected; the need not to be labeled as "deviant" or "dysfunctional"; and the need to have the rights and benefits, along with the responsibilities, of parenthood, partnership, and professional status. One of the members of the gay and lesbian focus group said "one is tolerated but not accepted." Another remark from this group was that one is "constantly having to filter out this part of your life.”

The African Americans who were interviewed did not feel welcomed by the local community. They felt prejudice and negative stereotyping against African Americans exists in this region. This was illustrated by the example one participant gave of how health care providers often assume the African American patient has a Medical Assistance card, indicating an erroneous assumption based on negative stereotyping.

\section{Bilingual Challenges Impede Optimal} Inclusion. One of the strongest challenges identified by the participants was the language barrier. Many voiced a commitment to the preservation of their home language. An Arabic Muslim noted he relies on the Arabic language to read the Qur'an. Many noted they speak their language of origin at home, such as Korean, Chinese, or Spanish, while they speak English at school and at work.

A number of the participants seemed to sense the use of their language was fading, due to a need to rely on English to survive in the American culture. Language problems were among the most significant and frequent barriers to health care cited by the participants. They noted how difficult it is for non-English speaking members of their community to relate to a health care professional.

Health Care Access Problems. There were mixed responses related to satisfaction with the local health care system. It was evident there were two main problems impeding satisfaction with medical services- language and residency status. Language barriers often prevented nonEnglish speaking members of the minority groups from effectively explaining their concerns to health care providers. Residency status was another large problem, particularly for members of the Hispanic group who may not have residency status in this country. One participant explained if one does not have a social security number, one cannot obtain health care. Participants who did not have health insurance noted they use the emergency rooms of hospitals if they need medical care. Lack of health insurance precluded them from making visits to a family physician's office.

For English-speaking minority group members who were either American citizens or had another type of official residency status, health care access was typically not a problem. Minority participants who were financially very limited often relied upon the free medical clinics in the region, and voiced satisfaction with these services. Inclusion was another issue related to health care access. One participant in the gay and lesbian focus group complained many health care forms do not include same-sex couples as a category.

\section{Discussion}

Qualitative focus group studies of this nature are intended to examine the unique experiences of individuals and populations in specific environments or circumstances. This study was designed to examine the lived experience of diverse cultural groups in northeastern Pennsylvania. Though it was not intended for generalization to the larger population, it was felt that some transferability of findings could be found. Therefore, external validation of the study was sought from an outside source- a qualitative researcher and professor from out of state who also was a health care professional. Selected excerpts from her e-mails appear in Figure 2, below. They are presented here because they further explore the issue of access to health care from a national perspective. In the e-mail excerpts, she presented some interesting experiences she had while working as an occupational therapist. For example, she talked 
about her work with immigrants in New York City's Chinatown who did not have health insurance and tended to self-medicate. She also discussed her experience with a new mother (who was non-English speaking) in urban Cleveland who was unaware of post-natal health care services. Furthermore, she gave credence to our study's finding about the resistance to pursue mental health services in the Asian population group.

These e-mail excerpts demonstrate how individuals from diverse cultures tend to face similar social, economic, and health access problems, whether they reside in northeastern Pennsylvania, New York City, or Cleveland. This external validation substantiates the findings of this regional study from a broader perspective. It reinforces this study's recommendation that the health care system needs to cross the language barrier to better serve diverse populations. It also shows the uniqueness of the customs of the contributor's own Asian group. As shown in the appendices of this report, just about all of the diverse cultures have their own unique set of traditions. As health care providers, we must come to know and respect these interesting aspects of being part of a distinct cultural group.

Efforts are needed to help individuals from diverse cultures gain both social acceptance and access to needed health care services. Health, human service, and educational planners in northeastern Pennsylvania may want to look into the possibility of providing more language interpreters in health care, offering weekend foreign-language schools for the children of immigrants, and providing after-birth resources for those needing these services. In addition, health care information should be provided in both English and native languages to enhance public access to health care education and community resources. These are all strategies provided elsewhere to individuals from diverse populations, and noted by the external contributor as being helpful services.

\section{Conclusion}

Unfortunately, this study indicated many of the participants did not feel welcomed by the people of northeastern Pennsylvania. They often tended to socialize within their respective minority groups, and not to mix with others residing in the area. The majority of those interviewed felt the existing local health care system was lacking in its ability to serve them, with language being seen as a primary barrier by many of these individuals. Many noted how the traditions and customs of their primary ethnic group were fading.

The findings of this study demonstrate the uniqueness of each of these local minority groups when contrasted with the mainstream population. Differences between the groups included education, class, language, religion, dress, food, customs, codes of conduct, and degree of acculturation. It is important for health care providers to become aware of these cultural and ethnic variations, as they may affect the care they are providing.

As follow-up to this study, educational sessions for health care providers to address these issues are now being conducted in northeastern Pennsylvania by members of the College Misericordia Diversity Institute. Future research is needed to monitor the extent to which the minority groups have been accepted by and integrated into the local culture, and to ultimately determine if they can more readily access needed health care services. Additional studies are needed to determine if progress is being made in fulfilling the health care needs of all ethnic, racial, and cultural minority groups living in Luzerne and Lackawanna County, and other parts of northeastern Pennsylvania. There should also be continual re-assessment of these needs. 
ON THE PROBLEM OF LACK OF HEALTH INSURANCE:

....I did get a chance to go over the Asian American piece and I LOVE it ... the 6 common themes are well-stated. They are so true. I kept nodding my head as I read through it. The detailed description of Asian American culture and health beliefs are so right. I agree with the socialization, leisure, and language information. You mentioned the issue of health care access is related to the individuals' residency status- I 100\% agree with it. When I was in NYC, there were many immigrants from mainland China without legal documents or residency status. Most of them live in Chinatown. They didn't have health insurance and usually didn’t go to see doctors for physical exams. They tended to self-medicate if minor illness occurred. If there was a serious sickness, they utilized the ER as a final resource.

\section{ON THE PROBLEM OF THE LANGUAGE BARRIER:}

...This also links to one of my experiences while working at a medical center in Cleveland as a home care occupational therapist. One time I got a phone call from a home care pediatric nurse who needed me to accompany her for a home visit because the newborn baby was very sick and the family did not speak English. The mother didn't go to OB/GYN for follow up during her pregnancy due to a lack of health insurance and the family was not aware of community resources available in the area.

Therefore, I think it is important for hospitals to recruit interpreters or bilingual health care professionals to break communication barriers in health care.

\section{ON CHINESE SCHOOLS FOR SCHOOL-AGE KIDS:}

...Changes in family dynamics between older generation and youngsters are interesting to review. Most of the weekend Chinese schools for kids are located in metropolitan areas (such as NYC, Philadelphia, LA,) and run by volunteers. Indianapolis has a Chinese association run by a non-profit organization dedicated to teaching kids Chinese. They have weekend Chinese schools in 4 different locations in Indianapolis, Indiana. Many members are parents who have adopted children from China, Korea, or other Asian countries. When I was reading through the section that described kids being required to call parents' friends "Uncle" or "Aunt”, I was smiling because it is so true. My family taught me to do this when I was growing up. We also now teach our daughter to say hello to people, even to strangers.

\section{ON AFTER-BIRTH CENTERS IN TAIWAN:}

...The health belief of Chinese people in pregnancy and childbirth may impact health care decisions here in the United States. It is common that new mothers stay home for a month after giving birth to a newborn. Therefore, it is popular in Taiwan that hospitals have affiliated after birth centers for new mothers to stay for a month to rest and nurture their babies. Babies usually stay with moms and there is 24 hour nursing coverage. It is not covered by third party payers but every one of my friends and family who has given birth has used this resource.

\section{ON CHINESE FOOD CUSTOMS:}

... (In the report) there is a session about the "cold" and "hot” food. I may raise a question as my family usually eats cold food in summer and hot food in winter. We tend to eat food to balance body for the seasonal changes of temperature in the environment.

\section{ON RECEPTION FROM NATIVES OF THIS COUNTRY:}

...I also may disagree with one participant's statement about the friendliness of people in PA, as I believe I have very good reflections toward people's friendliness in PA. I have had pretty good experiences with the persons I have met and worked with since coming to the United States. I guess personal incidents, communication barriers, feelings of isolation, and personal reflections may have an impact on this.

\section{ON RESISTANCE TO MENTAL HEALTH SERVICES:}

...One thing I also found interesting in the Chinese culture is their tendency to not seek professional help in the area of mental health. Social stigma has a lot to do with it, as well as health beliefs in diverse cultures. ...mental disorders and/or problems in mental health are viewed as caused by evil spirits- in Chinese culture- and may be cured by religious ceremonies. It is often uncommon for the family to seek professional help when facing some difficult crisis. Therefore, problems in marriage and/or issues in family dynamics are commonly covered up and not discussed with others outside of the family. When I was helping a Chinese doctoral student at another university for her doctoral dissertation as a peer reviewer, I remember this was a common response- Chinese people are more reluctant to seek professional help in the area of mental health.

\section{ON NEED FOR ENHANCEMENT OF SERVICES TO DIVERSE POPULATIONS:}

...I really LOVE your report. I am so inspired by all of you who take your time and offer your professional expertise to work on the project in order to better serve people from diverse cultures. As a new immigrant with a family, I am so touched. It lets my eyes watering. Please express my greatest appreciation to your team. THANK YOU. You definitely have my OK to use anything I wrote. It is an honor to me.

Figure 2

External Validation of Health Care Access Problems 
Furthermore, it is recommended that future research examine changing patterns in local population growth. For example, the African American participants in the study noted an increasing number of individuals of African heritage are immigrating to this area from other nations. This indicates there may be a growing need for the local health care system to effectively deal with problems such as language barriers and varying customs and traditions. Cioffi (2003) suggested the hiring of bilingual health care workers to assist nurses in an acute care setting in communicating with patients from diverse backgrounds. Additional strategies of this nature may be needed.

Finally, since the problems identified in northeastern Pennsylvania seem to be a trend in many parts of the nation, there should be an effort to see how other regions of the country are reacting to the challenge of increasing health care accessibility for diverse population groups. Green contended that minority group access to health care is a persistent and major problem (2003). Health care policy-making can be an effective tool for helping to remedy the equity problem which exists in the availability of health resources. Health care professionals and consumers are vital stake-holders in this process. They must use the political and legislative system to see that the necessary policies are developed and implemented in this regard. Matus (2003) called all healthcare administrators, managers, educators, and policy makers to build accepting and communicative healthcare environments which meet the needs of diverse populations. The future health and welfare of millions of United States citizens depends on this.

\section{References}

Cioffi, R. N. J. (2003). Communicating with culturally and linguistically diverse patients in an acute care setting: Nurses' experiences. International Journal of Nursing Studies, 40(3), 299-306.

Green, A. R. (2003). The human face of health disparities. Public Health Report, 118(4), 303-308.

Matus, J. C. (2003). The movement for diversity in health care management. Health Care Manager, 22(2), 117-121.

Wakefield, M. (2003). Change drivers for nursing and health care. Nursing Economics, 21(3), 150-151.

\section{Acknowledgements}

The College Misericordia Diversity Institute and the focus group research team would like to thank the Blue Cross Blue Ribbon Foundation for its support of this study. They also wish to thank the College Misericordia administration and Board of Trustees for their encouragement. The Blue Ribbon Grant focus group research team also appreciates the cooperation of Jewish Family Services, Geisinger Wyoming Valley Medical Center, the Mercy Health Care System, and the Wyoming Valley Health Care System. The contribution of Fengyi Kuo, a visiting assistant professor at the University of Indianapolis and a graduate student at the Indiana University Purdue University at Indianapolis, is also greatly appreciated. Lastly, the team wishes to gratefully acknowledge all of the focus group participants for their contribution to this research investigation.

\section{Author Note}

The Blue Ribbon Foundation of Blue Cross of Northeastern Pennsylvania provides financial support only and does not endorse the results of the project or program activity.

Author Information

Linda Trompetter, Ph.D.

Director of the Diversity Institute

College Misericordia

Dallas, PA 
Arthur Breese, M.S.

Assoc. Director of the Diversity Institute

College Misericordia

Dallas, PA

James Calderone, Ed.D.

Professor in Social Work

College Misericordia

Dallas, PA

Grace S. Fisher, Ed.D., OTR/L

Assistant Professor of Occupational Therapy

College Misericordia

Dallas, PA

Rodrigo Gereda

Victim/Offender Mediation, Divorce \& Custody Mediation

Peace Center

Wilkes-Barre, PA

Mari King, Ed.D.

Associate Professor of Medical Imaging

Health Sciences Division Chair

College Misericordia

Dallas, PA

Richard Kramer, CPA

Board of Directors

Jewish Family Service of Greater Wilkes-Barre

Wilkes-Barre, PA

Anne Lin, Pharm.D.

Chair and Professor of the Department of Pharmacy Practice

Wilkes University

Wilkes-Barre, PA

Hisham A. Nabaa, M.S.

Adjunct Faculty

Division of Engineering \& Physics

Wilkes University

Wilkes Barre, PA

Lalit Shah, Ed.D.

Associate Professor of Occupational Therapy

College Misericordia

Dallas, PA 
Theresa Tyler Smith

Director of HIV/AIDS Education

American Red Cross

Wilkes-Barre, PA

Sister Mayon Sylvain, RN, MPH

Leadership Team Member

Sisters of Mercy

Dallas, PA

Suzy Weinman, LSW- Social Worker

Jewish Family Service of Greater Wilkes-Barre

Wilkes-Barre, PA 


\section{Appendix A}

The African American Culture and Health Care Experience in Northeastern Pennsylvania

This is one of 7 appendices to a report from a northeastern Pennsylvania study called A Focus Group Study of Diverse Local Populations and Their Health Care Experiences in Northeastern Pennsylvania: Cross-Cultural Issues. The study was conducted with support from the Diversity Institute of College Misericordia and the Blue Ribbon Foundation of Blue Cross of Northeastern Pennsylvania. This particular report focuses on the findings from the African American focus group.

\section{Participants}

There were six members of the African American focus group: 5 females and 1 male. Their ages were $27,32,40,42,45$, and 54 . The yearly family income level of 4 of these participants was in the $\$ 21,000$ $\$ 50,000$ bracket. The yearly family income of 1 of the participants was in the $\$ 51,000$ - \$75,000 category. A sixth member of the group did not report an income level. The occupations of three of the participants were: consultant, residential living supervisor, and executive housekeeper. Two of the other participants were employed in higher education, and one was employed in customer service. The highest educational accomplishments reported by the participants included: one master's degree, three baccalaureate degrees, and two high school diplomas. There was wide variation in the amount of time the six participants lived locally: 2, 3, 4, 12, 14, and 32 years. The number of years they each resided in the United States was: 27, 32, 40, 42, 45, and 54 .

\section{African Americans in Northeastern Pennsylvania}

\section{Background of Focus Group Participants}

All of the focus group members said they came to northeastern Pennsylvania for a better life. They defined a better life as one which offers jobs, education, safe neighborhoods, and hospital care. All of them came from the southern United States. Five of the respondents said what attracted them to the north was the possibility of life without racial discrimination.

\section{Population Size and Income}

The size of the local Luzerne County African American population is approximately 7000. Most local African Americans reside in South Wilkes-Barre neighborhoods. The participants said the average income of local African Americans is approximately \$15,000.00.

\section{Local African American Language}

When asked about any unique features of their language, the interviewer (who was an African American) summarized participant responses by saying "Yes, it is defined as lax English. There are code words understood by the entire group. It’s similar to an in-group language.”

\section{Employment}

"Blue collar jobs" are major sources of employment for local African Americans. These include positions in housekeeping, restaurants, sales, construction, and assembly lines.

The older focus group members felt the man should provide the major source of income for the family. The younger focus group members felt both the man and woman are expected to work outside the home because of the recent demands for a productive life. When a woman has a child she is expected to fill the traditional role of a mother/wife. 


\section{Key Values Guiding Behavior}

Overall the group agreed their values are based on their religious beliefs, and thus are based either on the Bible or the Koran. These values include faith, integrity, respect for elders, and treating others the way they want to be treated. In general, the respondents agreed they do not categorize people by class. There is little talk about individual accomplishments, or saying "look what I did.”

\section{Religious Traditions}

The major religion practiced by local African Americans is Christianity. Although there are many sects in Christianity, the predominant sects in the African American community are Baptist and Methodist. The most significant holidays celebrated by the local African Americans are Christmas, Thanksgiving, and Dr. Martin Luther King's Day. It is very important for the extended family to get together over the holidays. Most of the holidays are celebrated by gathering for a meal. After the dinner many reminisce about the "good old days." Dress, especially when an individual is attending a religious ceremony, is formal. Recently this unspoken rule has become relaxed but it is still seen as disrespectful if you attend a formal religious ceremony in "street attire."

\section{Family Dynamics}

The African Americans in the focus group were raised either in single parent homes or in residences which also housed members of their extended family. Regardless of what the living arrangements were, they all seemed to believe in the African proverb that "it takes a village to raise a child." All of the African Americans said their extended family is very important to them.

Traditional gender roles are followed in local African American families. The women tend to do all the household chores and the men tend to do the physical chores. Nevertheless, the group voiced the need for caution in adhering to traditional gender roles when determining power in relationships. There are unwritten expectations of family member roles. An expectation of African American children is to take care of parents when they get older. When children decide to put their parents in a nursing home it is scowled upon by their community.

Key African American family decisions are made by the matriarch of the family. For example, when a family needs to make a decision they usually first seek advice from the eldest matriarch. Then they engage in a discussion with their spouse or partner and arrive at a compromise, if needed.

\section{Child-Rearing, Discipline, and Respect}

The local African Americans focus group participants believe in physical discipline. One stated: "Spare the rod, spoil the child." They said very rarely do they use "time out" as a means of discipline. It was noted the "spanking method" can be traced back to slavery when the masters whipped the slaves for socalled inappropriate behavior. This was a way of keeping them in control and in fear!

The African Americans said it is often important to address others by titles such as "Mr. or Mrs." or "Sister or Brother Jones." They felt talking back to your elders is very disrespectful.

\section{Pregnancy, Child Birth, and Circumcision}

The overall group agreed pregnancy (whether it is planned or unplanned) should never be terminated. They said one should just accept it and move on. For most African American males, circumcision occurs at the time of birth.

\section{Beliefs about Sexuality, Cohabitation, and Marriage}

Overall, the group agreed views on sexuality and marriage depend on one's age and generation. The older generation frowns upon cohabitation and children born outside of marriage. Generally homosexuality is not discussed within the African American family, expect for the church's view that it is 
an abomination. The younger generation is more accepting of homosexuality due to recent positive media exposure.

\section{Nutrition and Meal-Time Practices}

All of the African Americans reported it is customary to wash one's hands before sitting down and partaking in a meal. It is also customary for individuals to say a blessing before they eat. This can be said silently or aloud. Fasting is done for religious purposes. This is done often, if the individual is healthy. Usually one fasts for a reason, such as a miracle, healing, or deliverance from sin.

The African Americans reported much of their food is fried in deep lard or cooked with pork/fatback. This tradition can be traced back to slavery when the masters would provide the slaves with food "scraps" during food preparation. This is known as "soul food." The food not only supplied nutrition, it also offered spiritual significance.

\section{Touching and the Importance of Physical Distance}

Touching, in the African American community, is reserved for close acquaintances. However, during church services when the pastor encourages the parishioners to "pass the peace", individuals are more likely to give each other a hug.

\section{Socialization, Community Organizations, and Leisure Activities}

Members of the African American focus group reported involvement in the following organizations: N.A.A.C.P., Sister- Sister, Masons/Golden Rule Lodge, and Eastern Star. The group reported many leisure activities, including playing cards, seeing movies, attending afternoon church services, going to church picnics, and having weekly dinners with extended family.

The African Americans interviewed stated they tend to socialize more with other African Americans. All of the participants agreed their socialization with non-African Americans occurs through employment or ecumenical services.

\section{Reception from Luzerne County Community}

When asked if they were welcomed by the "natives" of the area, all of the respondents in the group replied with an empathic "NO!" They felt a major stressor of living here was being viewed by others as a group member rather than an individual. They also said they were tired of having to always educate the dominant group, rather than the dominant group seeking out the answers themselves. They said they could not live in this region unless they learned the nuances of the major cultural groups. They also noted the number of Confederate flags on homes and on cars, and said this reflects insensitivity towards African Americans.

\section{Health Practices and Beliefs}

Some common illnesses reported by this group were heart disease, high blood pressure, and diabetes. They said they seek a physician for medical services and a minister for psychological help. If the psychological problem is of an organic nature, such as bipolar illness, they do seek medical help. Remedies they use for both medical and psychological illness include their eating habits.

\section{Cleanliness}

Many of the respondents stated "Cleanliness is next to Godliness.” The kitchen and bathroom are always clean because they can be used by guests. Common personal hygiene routines include taking a bath or shower daily and washing one's hands after the use of the restroom. 


\section{Care at Home}

The focus group members said they tend to use home remedies before seeking the advice of medical practitioners. The primary care giver is the eldest matriarch in the home. Many of the respondents stated they use over-the-counter medications to improve their health before seeking a doctor. They also use nontraditional cures for earaches, teething, and muscle aches.

\section{Religion and Illness}

The African Americans looked at physical and mental disabilities from a religious perspective. They felt "God would never put on you more than you can bear." However, they were taught to look at disabilities as God's way of punishing your family. They also rely on "the laying on of hands"- which is based on a religious belief that God can heal you from anything. These believers feel "All you need is faith.”

\section{Perceptions of the Luzerne County Health Care System}

The group found the formal local health care system to be paternalistic, as reflected in the statement: "Do what I say and do not question it!” They also did not find it to be accessible unless you know someone in the system. They said this is the case even for those with health insurance. The newcomers felt they needed to drop a familiar name to navigate successfully within the system.

\section{Customs: Illness, Hospitalization, and Death}

The African Americans said, for optimal hospital care, daily visits to a sick person should be made. They voiced the existence of trust issues between their families and the health care system. In addition, it is traditional for both the extended family and the church family to visit the ill person. Food is usually brought in unless it has been prohibited by the primary doctor.

Death is viewed as a part of life, a celebration! Many African Americans celebrate death as a "home going service." The service is very upbeat and notes the steps of an individual's life. When there is a death in the family, everyone in the extended family attempts to get to the "home going service", regardless of their relationship to the deceased. The entire extended family is usually present for the service. This is part of the reason why many African Americans have their funeral/wake service weeks after the individual has died. The service is delayed until all the members of the family have been contacted to determine if they will be attending the service.

\section{Researcher Summary: African American Focus Group}

Key health issues and needs of Luzerne County African Americans include cardiovascular disease, high blood pressure, diabetes, testicular cancer, glaucoma, and auto-immune deficiency syndrome (AIDS). Issues in this population group needing more careful attention from health care professionals include a desire on their part to participate in health care decision making. Many of the participants voiced the need for health care professionals to treat them as a part of the medical team. Interviewees wanted to ask questions, choose alternatives, and, if necessary, get a second opinion.

Religion is an important influence on the health and illness beliefs of many African Americans. It is believed disorders- especially in children- may be attributed to their parents' transgressions and may need to be healed through prayer. For example, deformity, seizure disorders, and retardation in children may be interpreted as divine punishments for parental misdeeds. Home remedies and physician ministrations are considered powerless to cure someone who has been punished by God. Many believe only repentance (through a contact with God- directly or through the intercession of a faith healer) can effect a cure. 


\section{Recommendations for health care professionals working with this population are:}

1. Do not ignore race. Do not treat patients as if you do not see color. This can have devastating effects.

2. Understand religious traditions. For this population it is extremely necessary for health care professionals to take into account the religious tradition of the individual.

3. Be careful with terms. For example, do not say "you eat poorly” or "you eat badly.” This puts an immediate shield up between the patient and the health care professional.

4. Use titles. Address your patients with titles such as Mr., Mrs., Ms., Miss, Dr., etc.

5. Don't assume the patient's race. Ask them what they are such as African American, Black, Jamaican, African, Bi-racial etc. Hospital forms should be updated to include these categories. African American communities have become very diverse, especially with the recent arrival of people from Haiti, the Caribbean, and Africa.

6. Never refer to someone as a colored person!

7. Don't assume. Many African Americans will be similar in background to the caregiver, and many will be of different backgrounds. Whatever the race of the caregiver, no assumption should be made about the similarity or difference in background between caregiver and patient. With respect to healthrelated beliefs and practices, an African American patient may be as different from an African American caregiver as from a Caucasian, Hispanic, or Asian physician. On the other hand, an African American patient may be quite similar to the caregiver, regardless of the caregiver's race. It is the task of the caregiver to probe and listen carefully to the patient to determine the patient's expectations and beliefs.

8. Ask for causes. When taking the initial history and performing a physical examination, ask patients not only about their symptoms, but also if they know what caused the illness. Patients' answers may reveal whether they subscribe to a folk or magical belief system.

9. Listen without judgment. It is essential, during all stages of a consultation, for the health care professional to listen carefully and sympathetically. They need to refrain from expressing anything that might be interpreted as judgmental, patronizing, or ridiculing.

10. Carefully consider the cultural value of family dependency. Traditionally African Americans feel obligated to care for their parents and extended family members at home, rather than place them in an adult care facility. 


\section{Appendix B}

\section{The Arabic Muslim Culture and Health Care Experience in Northeastern Pennsylvania}

This is one of 7 appendices to a report from a northeastern Pennsylvania study called A Focus Group Study of Diverse Local Populations and Their Health Care Experiences in Northeastern Pennsylvania: Cross-Cultural Issues. The study was conducted with support from the Diversity Institute of College Misericordia and the Blue Ribbon Foundation of Blue Cross of Northeastern Pennsylvania. This particular report focuses on the findings from the Arabic Muslim focus group.

\section{Participants}

There were 3 participants in the Arabic Muslim focus group. All three were males. Their ages were 33, 37, and 48. One was an engineering instructor, one was a software engineer, and one was a chef. One of the participants reported an income in the $\$ 21,000$ - $\$ 50,000$ bracket, another was in the $\$ 51,000$ - $\$ 75,000$ category, and the third did not report his income. The highest educational levels achieved by the three were a master of science degree, a bachelor's degree, and "college." The three reported living in Luzerne County for 2, 10, and 14 years. The lengths of time they resided in the United States were 10, 18, and 20 years. Two of the participants reported their countries of origin- Egypt and Jordan. Background of Luzerne County Arabic Muslims

Luzerne County Arabic Muslims come from a variety of places all over the world. Some moved here to join relatives. Others had job or educational opportunities in the area. Local Arabic Muslims work in medical, educational, and other professional fields. Many are doctors and business owners. The focus group participants estimated there are about 200 Arabic Muslim families in Luzerne County. They estimated family incomes of this group at about $\$ 50,000$ or more.

\section{Language}

English is the most common language spoken by the Arabic Muslims in Luzerne County. However, it was noted these individuals come from many different language backgrounds. Arabic is the second most common language they use. The Qur'an (the holy book of the Islamic religion) and most prayers are in Arabic. Arabic Muslims feel it is good for their children to learn more than one language.

\section{Values}

The religion of Islam is the basis for the value system of Arabic Muslims. Basic values derived from the Qur' an are honesty, fairness, hospitality, charity, generosity, modesty in dress, social justice, compassion, and commitment to family and community.

Muslims believes only God can judge a person's piety and righteousness. Islam declares equality among people, and says humans should respect other humans. One participant noted "Islam does not distinguish between two races, or two groups of people, or between two colors." He illustrated this point by quoting the Islamic prophet Muhammad:

"O People! Your God is one: your father is one; no preference of an Arab neither over non-Arab nor of a non-Arab over an Arab or red over black or black over red except for the most righteous. Verily the most honored of you is the most righteous.”

This same participant proceeded to explain that Allah says in surat, Al-Hujurat, (verse 13):

"O Mankind! We have created you from a male and female, and made you into nations and tribes, that you may know one another. Verily, the most honorable of you in the sight of Allah is he who has most taqwa among of you. Verily, Allah is All-Knowing, All-aware.” 
Islam places great emphasis on cleanliness, in both its physical and spiritual aspects. Cleanliness is part of the Islamic faith. On the physical side, Islam requires the Muslim to clean his body, his clothes, his house, and the whole community. He is rewarded by God for doing so. While people generally consider cleanliness a desirable attribute, Islam insists on it, making it an indispensable fundamental of the faith. A Muslim is required to be pure physically and spiritually as well as morally. The following verses about cleanliness from Al-Qur'an were noted:

"Believers! When you prepare for prayer wash your faces and your hands up to the elbow, rub your heads with water and wash your feet up to the ankles. If you are impure bathe your whole body." (5:6) "Allah loves those who turn to Him constantly and He loves those who keep themselves pure and clean." $(2: 22)$

Respectful behavior in the Islamic tradition consists of demonstrating high moral character, ethical behavior, modesty, simplicity, and moderation. The focus group members cited values of trustworthiness, truthfulness, charity, cleanliness, kindness, and hard work. Islamic individuals are expected to show respect for the elderly, give kindness to the young, and offer help to the weak. Elders, no matter where they are from, are to be respected. Also, any new acquaintance is to be welcomed and respected. Islam, and the Arabic Muslim tradition, emphasize gentleness. One participant noted the following writings from the Qur'an:

"Show gentleness, for if gentleness is found in anything, it beautifies it and when it is taken out form anything it damages it."

He who is deprived of gentleness is deprived of good.”

Disrespectful behavior is seen by Islam as any behavior opposite to the ones described above. Undesired behaviors in Islam include humiliating others, destroying property, not listening, throwing or kicking things in anger, and fighting. The Islamic quotes below illustrate the behavioral code.

"Indecency disfigures everything and modesty enhances the charm of everything."

"Course talk does not come into anything without disgracing it, and modesty does not come into anything without adorning it.” (Narrated by Anas ibn Malik)

\section{Religious Traditions}

The predominant religion practiced by Arabic Muslims is Islam. The major holidays which are celebrated are Ramadhan, Eidul Fitr, and Eidul Adha. A mosque is the religious gathering place for Muslims. Rhamadhan is the ninth month of the Islamic lunar calendar. Muslims fast during the days of Rhamadhan and make special prayers at night.

At the conclusion of Ramadhan, on the first day of the tenth month of the lunar calendar, Muslims all over the world celebrate Eidul Fitr. This is one of the two main festivals of Islam. Eidul Adha is the second main annual celebration of Islam. Eidul Adha follows the day of Hajj or Pilgrimage. It begins on the 10th day of the 12th month of the Islamic lunar calendar. On Eidul Adha, like on the Eidul Fitr celebration, festivities begin with a prayer service held in an open place in the morning of the first day. This prayer is usually attended by a large number of Muslims.

\section{Clothing}


Muslim men and women must always dress conservatively when visiting a mosque, covering their arms and legs. Women may be asked to cover their hair when visiting a mosque. Some local Arabic Muslim women adhere to Muslim dress customs which include covering their body except their face.

\section{Family}

The family is the foundation of Islamic society. The peace and security offered by a stable family unit is greatly valued, and seen as essential for the spiritual growth of its members. A harmonious social order is created by the existence of extended families; children are treasured and rarely leave home until the time they marry.

Almost all Muslim families are made up of a married couple with at least three children living in one residence. Family and extended family are a vital part of a Muslim's life. In the Muslim family, one rarely finds an elderly parent in a nursing home. Older individuals are cared for by their children. In spite of the strain of this responsibility, the opportunity to care for your parents is considered an honor and blessing. It is viewed as an opportunity for great spiritual growth. In Islam, serving one's parents is a duty second to prayer, and it is their right to expect it. Muslim mothers in particular are honored.

Pregnancy is viewed as a blessing from God. Most local Arabic Muslims are "pro-life”, except when there is danger to the mother. The Qur' an says "Wealth and children are the adornment of the life of this world.” One participant said: “Abortion, in Islamic teaching, is murder. Killing any person is strongly condemned in the Qur'an. God has made life sacred...”

Male children are usually circumcised in Islamic families. Childbirth decisions are usually made by the woman giving birth. For childbirth, Islamic women usually feel more comfortable with a female physician.

The focus group participants reported child-rearing practices which are incentive-based, including the use of rewards and "time-outs." A slap on the lower body may be given to a child who is engaging in extreme misbehavior.

In the Islamic tradition, all family members are part of the decision-making process, with more emphasis on the decision of the parents. One participant in the focus group said family decisions are made by the husband and wife, but the woman's opinion is valued usually more than the man's. Gender roles were explained by the following Islamic verses:

"The believers, men and women, are protectors, one of another: they enjoin what is just and forbid what is evil: they observe regular prayers, practice regular charity, and obey Allah and His Messenger." (Qur'an 9: 71)

A focus group participant noted "Allah has created men and women as company for one another, and so that they can procreate and live in peace and tranquility according to the commandments of Allah and the directions of his Messenger.” He proceeded to quote the Qur'an:

"And among His signs is this, that He created for you mates among yourselves, that you may dwell in tranquility with them, and He has put love and mercy between your hearts. Undoubtedly in these are signs for those who reflect.” (30:21)

The importance of the institution of marriage receives its greatest emphasis from the following hadith of the Prophet:

"Marriage is my path. Whosoever keeps a way from it is not from me." 
There is no Islamic law stating people must get married, but most Muslims do. Marriage is sacred in this tradition. Sex outside of marriage is not allowed, and living single is not encouraged.

One participant noted homosexuality, bisexuality, and trans-sexuality are not allowed in Islam. Another said "Homosexuality is forbidden in Islam, but no one can judge you except God."

\section{Food}

Diet plays a very important role in the daily life of an Islamic believer. Muslims start their meals with the name of God and thank God after finishing their meals.

There are many verses in the Qur'an which draw man's attention toward his self and which invite him to carefully study his body and soul and the nature of their mutual relationship. For this reason Islam has prohibited certain foods due to their ill effects and permitted all other pure, good, and clean food products.

Alcohol is prohibited in Islam. One participant explained this is because the harms of alcohol have been shown to be greater than the benefits. He quoted the following Islamic verse:

"And eat and drink, but waste not in extravagance, certainly He (Allah) likes not those who waste in extravagance.” (7:31)

The Qur'an makes it clear as to what food is and is not permitted. Basically, all food is lawful and permitted except for the following: meat from swine (pork, ham); pork-based products and by-products (sausages, gelatin, etc.); animals improperly slaughtered, or already dead before slaughtering takes place; animals killed in the name of anyone other than Allah (for example, by anyone other than a Jew, Christian, or Muslim; or as part of a pagan sacrifice); intoxicants; blood and blood by-products; foods contaminated with any of the aforementioned products.

Fasting, literally defined, means to abstain completely from foods, drinks, intimate intercourse, and smoking, before the break of the dawn until sunset. Muslims fast during the entire month of Ramadan, the ninth month of the Islamic year.

\section{Touching and Physical Distance}

Any physical contact between unrelated men and women in marriage or family is forbidden by most Muslim scholars. Physical distance is required between men and women, as this makes them feel more comfortable. Close physical contact is disliked. Some also do not even practice hand shaking with members of the opposite sex. That is why it is recommended for a man not to extend his hand to a lady except if she initiates the hand shake. Arabic Muslim women are more comfortable with making physical contact with other women.

\section{Community}

Arabic Muslims are involved in local religious, professional, and health organizations. There is an Islamic Association of Northeastern Pennsylvania to which local Arabic Muslims belong. Most members of the local Arabic Muslim community are professors and professionals who belong to organizations relating to their field of work. Most members of the local Arabic Muslim community are involved with their mosque. The Arabic Muslims reported they socialize with non-Arabic Muslims "all the time, through relatives, co-workers, and neighbors.”

\section{Leisure}

Arabic Muslims in Luzerne County report participation in sports (such as soccer), outdoor activities, picnics, camping, and other health and fitness endeavors. They visit places such as amusement parks.

\section{Local Community’s Response to Arabic Muslims}


The participants reported there is a lack of cultural awareness among the natives of this region. However, they did say most of the professionals in Luzerne County are welcoming and open-minded. They noted a lack of knowledge about the true teachings of Islam. They felt the information which is being disseminated about Islam is alarming and distressing, and some of it is entirely false. They also said there is lack of understanding of Muslim female clothing and of Muslim prayer in schools and workplaces.

\section{Death and Dying}

One person in the Arabic Muslim focus group said "For the Muslim, the whole of this life constitutes a trial and a test for the human by means of which his final destiny is determined. For him, death is the return of the soul to its Creator, God, and the inevitability of death, and the Hereafter is never far from his consciousness. This serves to keep all of his life and deeds in perspective as he tries to live in preparedness for what is to come. In times of distress or illness, the Muslim finds the greatest solace and comfort in the remembrance of God. The severely ill person, who might be distracted by his pain, greatly appreciates a companion who can read the Qur' an to him and remind him of God. The Muslim must treat the dead body with gentleness and respect as if he or she was alive. Cremation is forbidden. Rather, the body is cleaned, scented, and covered with a clean cloth for burial. The body should be buried by Muslims as soon as possible." To Muslims, death is a truth. It is a transfer from this life to another lifeto a life which awaits the day of judgment.

\section{Health Care Experiences}

The local Arabic Muslims reported they use all of the medical centers in the Luzerne County area. There use no specific health care providers. The focus group members said the health care system in Luzerne County is average, and is accessible.

Health is viewed by Muslims as something bestowed by God. Muslims believe physical and mental health is something only God controls and gives or takes away. Muslims comfort those who are sick, saying illness "washes away sins and is a test from Allah." One participant noted "The Messenger Mohamed urges us to visit the sick because of the consolation it involves and the elimination of pain and the comfort for his soul and the fulfillment of his right. We have to advise the sick to be patient and to thank Allah for the aspired continuity of sound, health, and peace.

Muslims often send flowers to individuals who are ill. One participant said "Visiting the sick is a basic duty one Muslim has for another, and is not reserved only for close friends and family. Consequently, the Muslim patient will often have many visitors. For the Muslim, visiting a sick brother or sister in faith is a basic form of worship to bring one closer to God.” 


\section{Appendix C}

The Asian American (Chinese and Korean) Culture and Health Care Experience in Northeastern Pennsylvania

This is one of seven appendices to a report from a northeastern Pennsylvania study called "A Focus Group Study of Diverse Local Populations and Their Health Care Experiences in Northeastern Pennsylvania: Cross-Cultural Issues." The study was conducted with support from the Diversity Institute of College Misericordia and the Blue Ribbon Foundation of Blue Cross of Northeastern Pennsylvania. This particular report focuses on the findings from the Asian American (Chinese and Korean) focus group.

\section{Participants}

This report reviews the findings from three Chinese and three Korean participants. These individuals were members of one of the two Asian focus groups. (Asian Indians were the members of the other Asian focus group.) The three Chinese focus group participants arrived in this area through various routes. One participant received a Ph.D. and taught for 2 years in a nearby state before arriving to assume a faculty position at a local university.

Another Chinese participant's spouse was a computer analyst for the U.S. post office since 1989. Due to the consolidation of offices, the couple moved to Luzerne County. This participant was not currently employed, because she could not find opportunities here. She said she did work outside of the home when the couple lived in New York State. The third Chinese participant came to the U.S. on a student visa to attend a MBA program at a local university. This opportunity was part of an exchange program between the local school and a university in China.

The three Korean participants said their reasons for coming to Luzerne County included marriage and job opportunities. The wife of one participant remains in NJ with the couple's son because they did not like living here. All three participants were originally from Korea, then moved to other parts of the U.S., and then moved to Luzerne County.

\section{Socio-Economic and Employment Circumstances of Local Chinese and Korean Populations}

There was limited information available from the participants as it relates to the population size, employment status, and income levels achieved by members of this group. According to the participants, the estimated number of Chinese people in Luzerne County is difficult to ascertain and is complicated by the fact there are Vietnamese people here who are of Chinese descent and who can speak Chinese.

One participant estimated the family income of local Chinese families to be at least $\$ 76,000$ annually. The participants said Chinese waiters and waitresses in this area have a significantly lower income level than many Chinese who are in professional positions. One participant said many Chinese come here because of job or business opportunities. Local Chinese restaurants are a large source of employment for this population group. There are also transient local Chinese restaurant workers. They work in the WilkesBarre/Scranton area but go back to New York or Philadelphia on their days off. They live with their families in New York City or Philadelphia.

The Koreans said the family incomes in their population group vary. Locally, Koreans work in different types of jobs, both in the service industry or as professionals.

There are basically two Chinese employment groups- professionals and non-professionals. The professionals are in education or in the health care fields. Often the males are the professionals. 


\section{Language and Religious Differences}

The local Chinese and Korean participants described the unique experience of being a bilingual group. They also had a lot of information to share about their religious affiliations and customs.

\section{The Bilingual Experience}

The principle language of the local Chinese population was English. The older generation tries to preserve the Chinese Language. Mandarin Chinese may be spoken at home. The participants felt it was important to preserve their mother language, so they could communicate with relatives and friends. To them, it was as important as being able to speak English.

One of the participant's sons is autistic. Thirty years ago, when the child was diagnosed with the disorder, little was known about autism. At that time the participant was told by a social worker to not confuse his son and to use English only. As a result, both of his sons do not speak Chinese.

One participant noted there is no Chinese school in this area to help promote the native language. He assumed this is because there are not a lot of Chinese children in the area.

In interracial marriages involving a Korean, English is the primary language spoken. If both the husband and wife are Korean, English is spoken but Korean is the primary language. One participant emphasized it is extremely important the Korean culture be preserved. This participant noted this is difficult to do, and is accomplished at different levels in different families. One of the reasons for going to a Korean church is to preserve the culture. It is important to the Koreans to find ways to expose their children to the Korean culture, such as through church or school. A barrier in this regard is the lack of local diversity, although that is changing.

\section{Religious Diversity in Local Asian Population}

Many Chinese here are Christians, some of whom are Catholics. Others are Buddhists. The major religion for local Koreans is Christianity. The Koreans are usually members of Protestant denominations, rather than Catholic.

Local Chinese people have religious practices based on a mix of Confucius, Dao, and Buddhist beliefs. Major Chinese holidays are the Chinese New Year and the mid-August Moon Festival. In both cases, family togetherness is very important. At these times a lot of getting together parties are held for extended family, relatives, and friends. During the Chinese New Year, adults give children "lucky" money, wear new clothes, and eat candy. It is customary for individuals from some parts of China to eat dumplings at this time. During the Moon Festival people eat moon cakes which are made of bean paste with egg yolks. The Dragon Festival (May on the Lunar calendar) is also celebrated by the Chinese.

\section{The Family}

\section{Child Rearing: Respect and Discipline}

The participants felt the Chinese are slightly stricter with youngsters than the Americans are. They felt Chinese children are more disciplined. Chinese children must behave and respect others. Chinese children are taught to listen to parents and teachers.

Korean child-rearing is also strict. Children are taught to listen to parents. Children are expected to behave. The father is the disciplinarian.

In Chinese families, education is highly valued. Children must be good students. The arts are also important. If the family can afford it, children receive music lessons. 
Chinese youngsters are supposed to show respect for seniors. Ignoring them is disrespectful. Letting people walk in front of you and standing up when you greet somebody are respectful behaviors. Cursing is considered particularly disrespectful. It is important to address one's parents' friends as "uncle" and "aunt" even if they are not related. Others would be addressed as "Mr." or "Mrs.” It is disrespectful to refer to adults or elders by their first name. Children are taught to say hello to people.

In the Korean culture, words and tone of voice show respect. It is rude to ignore others. It is also rude to not use both hands to give people things. If you do not make eye contact it is rude.

\section{Marriage and Children}

The participants relayed their thoughts on marriage and children. They relayed much emphasis on the importance of the male-female couple and the traditional family unit.

\section{Beliefs about Pregnancy and Childbirth}

The Chinese believe birth control is important. Pregnancy is viewed as a happy situation. Child- birth is a big event and is energizing. After child -birth, it is customary for the Chinese mother to not leave the house for 1 month. It is a tradition for in-laws to come to help the new mother for the first month. The mother cannot leave the home or touch anything cold. She eats a lot of chicken soup, eggs, and Chinese herbs. The new mother only sponge bathes and does not shower or take a tub bath for 1 month after childbirth.

Among local Chinese, these traditions may be fading. One participant said because there were no elder family members here to teach his wife what she needed to do concerning having children, she did not follow Chinese customs.

\section{Relationships and Sexuality: Marriage and Children Predominant Way of Life}

The Chinese participants felt their approach to courtship and marriage was slightly more conservative than the community at large. However, they said people of Chinese heritage who are born in the U.S. are more open-minded than those born in China. Homosexuality is rarely recognized and accepted in the Chinese and Korean culture.

The Chinese feel courtship, marriage, and cohabitation decisions are up to individuals. However, in the Chinese culture children are rarely born outside of marriage. Marriage is the accepted way of life. It is not unusual for Chinese individuals to be single. However, there may be a lot of pressure for them to marry after a certain age. Very few Chinese people do not get married.

In the Korean culture, the first month after giving birth, the mother should not be exposed to the cold. There are special foods that should be eaten, such as seaweed soup to cleanse the blood. The new mother should eat hot foods in the summer and cold foods in the winter. Garlic is also viewed as something healthy to eat, as well as beans of all types.

The participants described how their families function. They described a decline in the traditional maledominated approach to family decision-making. They also discussed the challenges of being separated from their extended families.

\section{Variation in Family Decision Making Practices}

The participants said in the more educated families, decision-making is increasingly shared between the genders. Decision-making increasingly occurs via consultation between the Chinese husband and wife. It is now common for the husband and the wife to discuss the issues. The parents are the main decision makers. Other families may be more traditional in that the husband may be the main decision maker. 
The Korean husband and wife typically discuss issues together. Depending on the issue, husband and wife may play a different role in decision-making. Decisions related to children's issues are made by the wives. Men make the major decisions. All three Korean participants stated the Korean women are behind the men and are involved in making the smaller decisions. Healthcare decisions are made together.

\section{Younger Generations: Changing Decision-Making Ways}

In traditional Chinese culture, men have more authority in family decision-making and are viewed as the bread -winners. Chinese men are also responsible for work requiring physical strength, such as shoveling snow and cutting grass. Chinese women are responsible for cooking, cleaning and other household chores. The younger generations of Chinese do not adhere to these traditions as closely as their elders did.

\section{Often Separated from Extended Family}

The typical makeup of a local Chinese family is two parents and two children. The Chinese extended family is very important. However, the grandparents often still reside in China. If extended family members are nearby, the entire family gets together for important holidays. Close relationships with family members are very important. Extended family members help each other in times of crisis.

Only a small number of local Chinese families have extended family members living here too. The older Chinese don't want to stay here with their children, because they feel there is nothing in the area for them to do. One participant's mother stayed for a short time and moved to California because there she can get Chinese television stations and food.

The nuclear family is the typical Korean family unit. There are not many extended Korean families here. The participants have all been away from their extended families for a long time. However, the extended family is very important in this culture.

\section{Value Systems}

The participants explained the key values of their cultures. Their remarks indicate high value is placed on respect for elders and authority, as well as on education.

\section{Respect for Elders and Authority}

It is important to have and to demonstrate respect for elders, authority, and the law. The Chinese participants said they often adhere to Confucius, Dao and Buddhist beliefs. These include respect for order, elders, and authority. Dao beliefs emphasize the importance of nature. Both the Chinese and the Koreans ask fewer questions than Americans. The Koreans said they place high value on showing respect for elders and authority.

\section{Perspective on Class Issues: Education and Income Important}

The participants said they tend to classify people as professionals and non-professionals. The more education a Chinese person has, the more he or she is respected. The Chinese categorize people according to their educational level, socioeconomic status, and family background.

Koreans classify people primarily according to their education. Education is viewed as very important. Individuals with greater educational backgrounds are highly respected. The second way in which Korean people classify people is by income. The third way is by religion. 


\section{Customs and Traditions}

The participants described customs and traditions from their cultures. These included tendencies to be less physically demonstrative, appreciation for home-cooked Asian foods, and dedication to discipline in child-rearing.

\section{Less Touching and Physical Contact}

Many Chinese are more reserved. Chinese people usually maintain a certain physical distance unless they are good friends. Touching is rare, particularly between the sexes. People don't kiss or hug each other. Even hugging between Chinese parents and children occurs less.

The Chinese prefer less physical contact, even from health care workers. If necessary it is acceptable for a physician to touch a patient, after a relationship has been developed.

In the Korean culture, there is little or no touching between members of the same sex. However, Korean women tend to touch each other more than men do.

\section{Food, Dietary Habits, and Mealtime Traditions}

Generally speaking, the diet of the local Chinese people is very light. It includes less salt, sugar, fat, and meat than the American diet. The Chinese diet also includes more vegetables. The local Chinese feel they eat a more healthy diet than the Americans. They state they eat less fast food, and more fresh fruits and fish. Tofu is a part of their diet. The Chinese don't eat very many canned and processed foods. Some families do use a lot of Chinese sauces, which may have high sodium content. The Chinese make a lot of meals via stir-frying.

Rice is the primary staple in the Korean diet. Koreans eat a great deal of vegetables, and eat less sweet things than Americans. Due to their use of preserved foods, sauces and spices, there may be more sodium in the Korean diet. Food is an important part of any Korean gathering. Rice or noodles are eaten everyday by the Chinese. Snacks are usually buns, rice cakes, watermelon seeds, dried fruits, and peanuts. There is a variety of food in the Chinese diet. There are more vegetables, protein, dried fruits, and nuts. Table manners are important. Chinese people are concerned with cleanliness. They like to be clean. Cleanliness plays an important part in Chinese social customs. It makes the first impression.

Many Chinese people believe eating the right food can prevent sickness. Nutritious food promotes health. For example, celery prevents high blood pressure. The Chinese believe in "hot" and "cold" foods. Eating a "cold" food will counteract a "hot" illness. Watermelon is a cold food, crabs are a cold food. One would drink alcohol when eating crabs to increase the "heat."

For the Koreans, the biggest meal is in the morning. The older Korean generations who are here keep this tradition alive.

\section{Leisure, Socialization, and Community Involvement}

The participants described their engagement in a wide variety of social and leisure activities. However, they show limited involvement in local and regional community organizations within the larger nonAsian community. This lack of community integration may reflect a problem in the receptiveness of area natives toward the Chinese and the Koreans.

\section{Variety of Leisure Activities}

The Chinese participants had a variety of leisure pursuits. These included attending dinners and picnics; reading news about what is happening in places like Taiwan, China, and Hong Kong; watching Chinese movies, television, talk shows, and video tapes; traveling; and visiting relatives or friends. They also 
liked to go shopping. One participant said she liked to grocery shop in New York, New Jersey, or Philadelphia because there are not any Asian grocery stores here. The Chinese participants say their group does not engage in many sports but several local Chinese people do play tennis together. Each Sunday, there is a group of Chinese people who also play ping-pong together.

For the Koreans, picnics are a common way to relax. Most activities of the Korean families revolve around the activities of their children.

\section{Socialization- With Other Chinese or Koreans and with Colleagues}

The Chinese participants tended to socialize within the Chinese group. This is primarily because of the language barrier. Even though a Chinese person knows the English language and has worked outside the home, language can still be a problem. The Chinese person may not feel as comfortable interacting with people outside of her group because of cultural differences. Some Chinese people feel isolated.

One participant said she feels comfortable interacting with non-Chinese people. She came to the U.S. knowing she will see people from different countries. She said she is interested in learning about other cultures and customs.

Korean professionals tend to socialize with their colleagues. The Korean participants said where they work determines with whom they socialize.

\section{Limited Involvement in Local Clubs and Community Organizations}

The participants noted limited involvement of the Chinese in local clubs and community groups. One participant was a councilman for 1 four-year term in a local borough because no one else wanted to do it. He said most local Chinese do not participate in community organizations; only a few do.

Clubs and community groups in which the participants participated included a Chinese American Association and a Diabetic Group. The local Chinese Association has approximately 30 members. The member of the Diabetic Group said she is the only Chinese person in the group, but feels comfortable with the people in it.

The primary community organization for the Koreans is the church. The other is a Korean language school that takes place at a local college; there are 8 children enrolled in the school.

Life in Luzerne County: Mixed Reception and Not Always Easy

One participant said she found Pennsylvania people are not so friendly to strangers. Another said when she is shopping she sometimes gets unfriendly looks. The participants seemed to feel people here are not open-minded. They are more conservative and are not as accepting of people who are different. Another said he had not experienced discrimination, perhaps due to his professional position.

The Chinese participants felt one of the stressors in the area is trying to find employment. There are not many professional jobs in the region. For the Chinese, these difficulties may be compounded by a native perception that jobs are being taken away by outsiders.

The Koreans said they usually feel welcomed at work. However, one Korean participant remembered a time on Public Square when she was accused of taking jobs away from Americans. One participant said the person living next door to her hated her because she is Korean. She said although she moved her a while ago, she still doesn't feel at home here.

Another participant said the first two years of living here were an adjustment period. This person liked it here because there is less traffic than in NJ. This person also enjoyed the fresh air and availability of golf 
in this region. Two of the participants said they miss living around their own people. One participant said he misses Korean cultural activities, stores, and people.

Health Care and the Local Chinese and Korean Populations

The participants described reliance on a mix of both ancient and modern health care and medical interventions. They admitted the problem of mental illness has yet to be adequately acknowledged in their population group. Although many of them are satisfied with the local health care system, they did indicate language barriers are often still a problem for individuals from their culture who do not speak English adequately.

\section{Health Care Practices}

Chinese usually go to the family doctor first. However, they tend to wait in some cases before calling a physician. Usually, the Chinese wife or mother is the primary caregiver in the home. The caregiver responsibility is shared by Korean mothers.

The Chinese participants said they turn to available local health care professionals for help when needed. Hypertension seems to be a common illness in the local Chinese population. Herbal remedies are used by some Chinese.

The Chinese do not openly accept mental illness. There is more stigma and shame associated with it. Therefore, they tend to hide mental illness. The Chinese view people with mental disorders differently than the Americans, and are not as accepting of mental problems. The Chinese are less likely to seek help from psychiatrists.

The Koreans said peptic ulcer disease, diabetes, and hypertension are the major illnesses. They said when they are ill it is customary to pray first and then visit a doctor.

Exercise practices of the local Chinese include walking, Tai-Chi, playing tennis, table tennis, and golf.

\section{Illness, Hospitalization, Death and Dying}

When Chinese people are ill, some may send them fresh fruits, flowers, and cards. It depends on the seriousness of the illness. If it is not serious, the Chinese may just call the person to show they care. If it is serious, both the Chinese and the Koreans will usually visit the ill person.

\section{Close family and friends visit the dying person}

The Chinese do not engage in singing or laughing at the viewing or the funeral. It is important to show sympathy and sadness. Services are held according to the traditions of the family's religion. Family members, extended family, and friends visit to pay final respects. In Buddhist families, the monks go to the funeral and there must be a seven-day wait before cremation.

When death occurs, a Korean tradition is that on the third day you gather for worship and on the 49th day you gather again. However, this tradition is not followed by many younger Koreans.

\section{Feelings about the Luzerne County Health Care System}

Both the Chinese and the Koreans are generally satisfied with the local health care system. They feel the system is reasonably accessible. They did say there are time delays. It is often difficult to get appointments. One participant said the local health care system is not as convenient as it is in New York. This person said in New York blood tests and other procedures can be done in a doctor's office. Here, you must go to a lab or to a hospital. Overall, the primary barrier to health care for the local Chinese is language. They said health care is not as good for those who are limited in their ability to speak English. 


\section{Interviewer Summary: Asian American Focus Group -(Chinese and Korean)}

One of the Chinese participants resided in this area and the U.S. for a long time. Isolation from others of similar heritage (due to the small size of the Chinese population here), has resulted in that participant no longer following many Chinese customs. When the participants had no people with whom to share their customs, and when there was no one to reinforce those customs, the local Chinese tended to assume a more American lifestyle. Many of the responses of the Chinese participants depended upon how much contact they have with their extended family. Additionally, some participants were not taught Chinese customs when they were young. Families who resided here for a long time relied less on Chinese traditions. One participant said Chinese people in this area tend not to be new immigrants, and therefore may not actively practice Chinese customs.

Preserving the Korean culture for their children was viewed as important by the participants, despite having lived in the U.S. for many years. There was expressed concern about the lack of a large Korean community and culture in the Luzerne county area. However, all three Korean participants indicated the younger generation do not follow as much of the traditional Korean ways as the older generation. 


\section{Appendix D}

The Gay and Lesbian Culture and Health Care Experience in Northeastern Pennsylvania

This is one of seven appendices to a report from a northeastern Pennsylvania study called "A Focus Group Study of Diverse Local Populations and Their Health Care Experiences in Northeastern Pennsylvania: Cross-Cultural Issues." The study was conducted with support from the Diversity Institute of College Misericordia and the Blue Ribbon Foundation of Blue Cross of Northeastern Pennsylvania. This particular report focuses on the findings from the Gay and Lesbian focus group.

\section{Participants}

There were a total of five participants in the gay and lesbian focus group - four women and one man. The age range of the group was between 38 - 44 years, and all but one lived in Luzerne County for most or all of their lives (the range in years lived in Luzerne County: 4 - 40 years). All of the participants had graduate degrees, with one holding the doctorate degree. Occupationally, the group was employed mainly in human service work, with one of the participants being self-employed in a private business. The participants' range in income was between $\$ 30,000$ - $\$ 76,000$. Four of the participants are partnered.

\section{Community Acceptance}

The participants generally do not find Luzerne County a "gay friendly" place to live. Comments such as "one is okay as long as one doesn't talk about one's sexual orientation / lifestyle", and one has to "go back into the closet" seemed to capture the community climate. As one participant put it, "You live in fear of exposure."

\section{Important Issues}

Concern for one's safety and the safety of one's children was a major issue. Related to this was the need to be vigilant, lest one expose oneself or one's loved ones to physical or emotional violence. This might manifest in exclusion, verbal indignities, vandalism, and assault. In addition, concerns about one's job security, one's right to stay involved with one's partner's/children's lives, and one's rights to share in the financial benefits of one's loved ones were expressed. Examples of the above include participants' experiences of home vandalism, job termination, difficulties with child custody, problems with hospital visitation, and exclusion of partners at significant moments. The term "gaydar" was mentioned by all as either an "intuitive sense" someone might be gay or lesbian, or someone might either be open or not to their sexual orientation issues. This term is based on the notion one needs to have "radar" ("gaydar") in order to remain vigilant to possible uncomfortable or even threatening situations. The need to be vigilant continues even in interactions with health care professionals, as will be addressed further in this section.

\section{Family Roles and Decision-Making}

Overall, participants valued flexibility in gender roles, with a high value placed on openness to individual differences and respect for those differences. The one male indicated he thought some gay men were more concerned about traditional gender roles, with one assuming a more "masculine" and the other assuming a more "feminine" persona. Generally, joint decision-making was important in couple decisionmaking and open dialog was valued. Concerning child-rearing, age appropriate boundaries and open dialogue appeared to be important. Issues regarding sexual orientation and family constellation are discussed as they arise. Again, the need to be vigilant about the possibility of their children or partner being put in a threatening situation was considered important. One parent talked of her daughter's encounter with peers, as she defended her family against verbal indignities. 


\section{Key Values}

Some important values expressed by these participants included respect for differences, inclusion, open dialog, independence, flexibility in gender roles and in social interactions, joint decision-making, acceptance and affirmation of those who are different, welcoming newcomers, courtesy, prejudice reduction efforts, and openness to new ways of thinking.

\section{The Respect-Disrespect Continuum}

The following behaviors were considered to be respectful by the participants: (a) creating a climate where one can comfortably be who they are, (b) including one's partner in the conversation and in decisionmaking, (c) using inclusive language, (d) acknowledgement of one’s family constellation, and (e) recognition of one's individuality.

The following are behaviors which the participants considered to be disrespectful: (a) bigoted language, such as "dyke" or "lesbo", (b) "gay thinking"- that is, focusing solely or primarily on genital sexuality, (c) sexual aggressiveness, (d) bigoted jokes, (e) exclusive language, such as health questions which do not have appropriate options from which to choose, (f) assumptions that influence others' behaviors, prior to knowing the participant as an individual, (g) labeling someone who is gay or lesbian as "sexually deviant" or "disturbed", and (h) social exclusion and dividing lines based on cliques.

\section{Stressors}

The following were mentioned as significant stressors, which significantly affect quality of life: (a) slowness of change in the acceptance of people who are sexually different, (b) constant vigilance concerning individual / family safety, (c) emotional, social, legal, physical, and economic vulnerability, (d) lack of support groups, (e) subtle discrimination where "one is tolerated, but not accepted", (f) many unsafe places, including houses of worship, (g) lack of positive images of people who are sexually different in society at large, (h) decisions being "second-guessed" because of one's sexual orientation or family constellation, (i) constantly having to "filter out this part of your life”, (j) labels which are attributed to people who are sexually different, and $(\mathrm{k})$ rigid gender roles reinforced in society. Interviewer Summary- Gay and Lesbian Focus Group

The participants discussed their experiences with the health care system locally and their reactions ranged from "good" to "unwelcoming." The following summarizes the participants' major concerns and recommendations relating to the provision of health care:

Health care needs include a welcoming environment in emergency rooms and hospital wings, where one's partners can be treated with respect and can be included as per the wishes of the patient. It might be helpful to remember many people who are sexually different are sensitive to subtle clues that their presence, the presence of their significant others, and their health care concerns are not taken seriously and respectfully.

There is the need for accurate information concerning human immuno-deficiency virus (HIV) and autoimmune disease syndrome (AIDS), sexually transmitted diseases, options for alcohol and drug addiction, and "safe sex." Some people who are sexually different will deny the stress of a non-accepting social environment and will not respond early enough to problems with depression, anger, and relationship difficulties.

Hospital forms and questions asked during health interviews need to be constructed to be relevant to all. There should not be the assumption all people are heterosexual; or if one is gay or lesbian they are not in a committed relationship; or single people or partners who are gay or lesbian are not parents. Good observation skills and cultural sensitivity are needed. In addition, it is important to remember some people who are sexually different may be reluctant to discuss their family lives and sexual concerns for fear of 
“exposure.” If one is asked if they are "sexually active," he or she might not relate this question to their particular sexual experience with a same-sex partner, or may simply be afraid responding honestly will be too threatening for them or the health care provider. The establishment of a safe environment, based on respect, confidentiality, and trust may take some work on everyone’s part. Open dialog is essential.

It is important for health care professionals to remember the spiritual needs of the patient. A number of people value their spirituality, even though their experiences with organized religion may be strained. Some patients may be involved in alternative healing practices important to note for an effective health assessment.

It is important for health care providers to address their own feelings about the sexual orientations and identities their patients present. How do old images, stereotypes, and fears get in the way of listening and responding effectively to those who are being treated? Sometimes the health care provider must recognize his or her limitations and ask the patient for assistance in correctly understanding health concerns.

Overall, the participants interviewed stressed the importance of a safe, respectful, and open environment where information can be shared honestly and without a judgmental attitude. The person who is served is not made to feel "deviant" or in need of "sexual counseling” simply because of his or her sexual orientation. This welcoming environment is one that supports the patient's ability to become actively involved in the health care process. When appropriate, health care providers need to include the "significant others" of their gay and lesbian clients in making important medical and health-related decisions. 


\section{Appendix E}

\section{The Hispanic American Culture and Health Care Experience in Northeastern Pennsylvania}

This is one of seven appendices to a report from a northeastern Pennsylvania study called A Focus Group Study of Diverse Local Populations and Their Health Care Experiences in Northeastern Pennsylvania: Cross-Cultural Issues. The study was conducted with support from the Diversity Institute of College Misericordia and the Blue Ribbon Foundation of Blue Cross of Northeastern Pennsylvania. This particular report focuses on the findings from the Hispanic focus group.

Participants

The Hispanic American participants in the focus group study were represented by four distinct groups: Argentineans, Dominicans, Mexicans, and Puerto Ricans.

\section{Argentineans}

Two participants, a male and a female (who were husband and wife), represented the Argentinean population in the focus group study. Each of these participants was 30 years old. They identified their family income as less than $\$ 20,000$ per year. One of the participants worked in the home care field, and the other cleaned a surgery department for employment. The highest educational level completed by one of the Argentinean participants was the third year of high school, and the other completed some teacher training. At the time of the interviews, each of these participants resided in Luzerne County, and the United States, for $2 \frac{1}{2} 2$ years.

\section{Dominicans}

Five participants, 2 males and 3 females, represented the Dominican group in the focus group investigation. These participants' ages ranged from 30 to 49 years. Four of the Dominican participants identified their family income as $\$ 20,000.00$ and under. One of the participants revealed a family income of between $\$ 21,000$ and \$50,000. Employment categories/settings for the Dominican participants included quality control; trainer in a meat factory; meat processing; home care; and casino work. The highest educational accomplishment of the Dominican participants was a four-year Bachelor of Arts degree earned by one of them. Another participant had a two-year college degree, and the third had some university training. The fourth participant completed high school, and a fifth participant completed the ninth grade. At the time of the interviews, two of the Dominican participants resided in Luzerne County for two years. The other participants did not reveal how long they lived in Luzerne County or in the United States.

\section{Mexicans}

Four Mexican participants, one male and three females, were involved in the focus group study. Their ages were 28, 38, 47, and 60 years. One Mexican participant stated a family income of $\$ 20,000$ and under; another's stated income was in the \$21,000-50,000 range; a third Mexican's family income was in the $\$ 51,000-75,000$ bracket; and the last participant's income was listed as over $\$ 76,000$. The employment status of the Mexican participants included: one unemployed, one working in the field of education, one self-employed consultant; and one producer of television commercials. Two members of the Mexican participant group completed master's degrees; the highest educational achievement of another was a four-year degree; the third participant completed grade six. Two of the Mexican participants resided in Luzerne County for 3 years. One resided here for 14 years. The fourth resided in Luzerne County for 18 years. One of the Mexican participants lived in the United States for 8 years; one lived her for 15 years; a third lived here for 47 years; and the fourth lived in the United States for 60 years. 


\section{Puerto Ricans}

Two Puerto-Rican females, ages 28 and 54 years, were interviewed in the focus group study. One of these participants stated a family income of less than $\$ 20,000$. The other had a family income of over $\$ 76,000$. One of the Puerto-Rican participants worked as an office manager; the other was a student support specialist. One completed 20 credits toward her master's degree. The other completed 12th grade. One of the Puerto-Rican participants resided in Luzerne County for 2 years, and the other for 10 years. One resided in the U.S. for 12 years, and the other for 28 years.

\section{Family and Friends Attract Hispanic Participants to this Area}

The two Argentinean participants stated although they had other contacts in various places, such as Washington, DC, and Miami, they chose to leave Argentina and come to Luzerne County. They had friends who attracted them here, and also wanted a better life.

The Dominicans reported friends and family played the largest role in their decision to move to Luzerne County. One participant's mother talked that person into coming here. Others had family here already, or came here with their family. One reported her husband brought her here. Most of the participants reported coming here from New York, but some came directly from the Dominican Republic. They were attracted here by low rent, a calm and better life, and plentiful work.

The Mexicans reported they came here from New York, New Jersey, Texas, Florida, California, and Mexico. They were attracted here by relatives, jobs, a better atmosphere, educational opportunities, low crime, better housing, tranquility, and security.

The Puerto Rican participants said they arrived in Luzerne County from Puerto Rico and other parts of the United States. They were attracted to the area by jobs and family connections.

Characteristics of the Local Hispanic Americans

\section{Population Size and Family Income}

The Hispanic focus group participants all resided in Luzerne County. The Argentineans stated there are about 10-15 people from Argentina living in Luzerne County, mainly in Wilkes-Barre. They said the typical family income here for persons of Argentinean heritage is about $\$ 20,000$ or less per year.

The Dominicans estimated the size of their population group in Luzerne County to be over 20,000. They said many Dominicans are moving to this area. The participants felt the majority of factory workers in Luzerne County are Dominican, and estimated this figure at over $90 \%$. They said the majority of the Luzerne County Dominican population resides in cities, particularly in Hazleton.

The Mexican participants said there are over 25,000 people from Mexico in Luzerne County. They are scattered throughout the area, but they mostly reside in Wilkes-Barre.

The Puerto Rican participants said in Luzerne County many members of their culture reside in Scranton, Wilkes-Barre, and Hazleton. They estimated a family income of about \$1200 per month for most members of their population.

\section{Employment}

The major sources of employment for the Argentineans in Luzerne County included factories and restaurants. They stated language is often a barrier to employment. They said typically both husband and wife seek work outside of the home. 
Three of the participants stated factories were the main employment setting for the Dominicans in Luzerne County. Another said Dominicans will work at anything. The participants said all adults in this population seek work outside of the home.

The Mexican participants reported they work in factories, restaurants, agriculture, service jobs, warehouses, kitchens, and transportation. All adults in this group typically seek work outside of the home.

A major local employer of the Puerto Rican groups locally is Excel Co. The participants said the level of education often determines if individuals in the Puerto Rican culture work outside of the home.

\section{The Home Language- Spanish}

The home language spoken by the Argentineans in Luzerne County is Spanish. They stated it is important for them to preserve their home language.

The home language of two of the Dominican participants was Spanish and English; three participants said their home language was Spanish. Preservation of the Spanish language was viewed as very important to these participants. Some noted they speak only Spanish when communicating with each other.

The Mexican participants reported Spanish as their home language. Some spoke only Spanish at home. Some of the parents/guardians do not have a choice; they only know Spanish. The preservation of the Spanish language was very important to this group.

The home language of the Puerto Rican group is Spanish. They felt the preservation of the home language is important because "through that language we transmit the culture." Language barriers in this region were a problem for the Puerto Rican group.

\section{Importance of Religion}

The Argentineans stated religions practiced by the Argentineans in Luzerne County include Jehovah's Witnesses, among others. They said their most significant religious celebrations are during Good Friday and Easter. These are special times of remembrance.

The predominant religion practiced by the Dominican group was Catholic. Death and dying customs of the Dominican population are very much tied to religion. They believe: "We have to die to reunite with Our Lord.” Singing and praying in the home are important activities. A 24-hour vigil is conducted at the home (with the deceased present), a funeral is held at a church, and burial occurs in a religious cemetery. Every month there is an "anniversary" memorial to the deceased individual, and a larger gathering is held after the one-year anniversary of the death.

The Mexican participants largely practiced Catholicism, and both of the Puerto Rican participants practiced Catholicism.

\section{Key Values and Traditions}

Key values guiding behavior in the Argentinean cultural group include trying to be good neighbors. The Jehovah's Witness religion guided the morality of these study participants. They noted the importance of reading the Bible. If Argentineans are not residing with their parents, an important tradition is to visit parents on Sundays for dinner. The participants stated they prefer home-cooked foods. They miss eating foods from Argentina, and do not like fast food or canned food. An important meal tradition is eating with the extended family on Sundays. The main meal of the participants in their home country was at noon. Now it is eaten later- in the evening. They stated in their culture affection is expressed by kissing on the cheek and by hand-shaking (for new acquaintances). Cleanliness was viewed as highly important. 
The Dominican participants said they eat fresh food, not canned foods. Learning about food and proper nutrition is important to them. One person said they do not eat pizza, but they do eat rice and beans. Fasting during Lent is important. They noted a preference for typical Dominican foods: fruits, vegetables, chicken, and fish. It was important for some members of this group to eat three meals together every day. Important mealtime traditions practiced by this group included eating together; having their main meal at noon; celebrating "everything through our food"; having a large meal on Dec. 24 with the whole family; and offering food to those who visit.

Key traditions guiding the behavior of members of the Dominican group revolved around family, food, music, and church. Important values included honesty, faith, family, and working responsibly. Grandparents and elders play an important role.

The Dominican participants said people in their culture are very affectionate and touch often. This includes kissing, hugs, and holding each other.

Important social customs regarding cleanliness in the Dominican group include an emphasis on a clean home and workplace. One person said it is horrible when dogs and cats are allowed inside, as they are dirty. They said "we are very clean.” Regular bathing and hand washing are important.

The most significant Dominican holidays/traditions are Sundays; Christmas Holy Week; Noche Bueno (on December 24 - a thanksgiving celebration); New Year's Day; Dominican Independence Day (February 27); and Our Lady of Altagracia (January 21).

Although four of the Dominican participants said they tended not to categorize people by class, they did say class differences are noted. In particular, they noticed when individuals do not have proper manners.

Respectful behavior in the Dominican population is demonstrated by speaking clearly and without cursing; honoring what the elderly do and say; and behaving cordially, kindly, and with composure. Particularly "disrespectful behavior" includes not honoring your parents; ignoring others; offending one's mother; and disobeying parents.

Important customs when Dominican family or friends are ill and/or hospitalized include paying lots of visits; bringing food, balloons, and gifts; and taking communion.

Important holidays for the Mexican participants included Christmas - Posadas; Lent; Semana Santa/Holy Week; Navidad/Christmas; Dia de los Reyes Magos/Jan. 6th, Wise Kings; Dia de los Muertos y, 2 DeNov/Day of the Death; 5 de Mayo; victory against French invasion; and Dia de las Madres/(May) Mother's Day. Important religious practices included Devotion to Our Mother Guadalupe, and attending Mass.

The Mexicans participants noted the importance of simple, modest clothing.The Mexicans in the focus groups stated they strongly prefer their own food. This consists of a balanced diet of fruits, vegetables, and grain. They use lots of spice. One said "Food governs all; we live life through our food.” They also often fast. In general, in a Hispanic home the food is fully processed and cooked at home. There is no use of canned food. Food has to be fresh and made at home. The participants said they eat large homecooked meals. There are ethnic food and traditions associated with every holiday. Food plays an important role in religious festivities and celebrations.

Respectful behavior is extremely important in the Mexican culture. Dignity and honor must be preserved. They are comfortable in being close in proximity with each other. One said: "We are very touchy people 
and believe Americans are very cold.” A kiss on a cheek is a sign of affection. Respectful behavior involves not looking at the eyes and not talking back.

The Mexican participants said they are very clean people. They keep themselves, their children, their homes and their workplaces very clean. One person said, "We believe Americans take better care of their animals than they do of their children.” Cleanliness is stressed every day/with social gatherings. The participants said Hispanics are known for their personal cleanliness.

Visitors are always welcomed in the Mexican culture. It is important to share whatever one has. Washing hands is an important Mexican practice. Thanking God is important. Prayers occur before mealtime. Women serve meals; many dishes are prepared and served individually. It is important to eat together. On Sundays others are invited to join.

Key values of the Mexican focus group were humility, respect, honor, dignity, solidarity, hard and honest work, family, faith, children, religion, religious values, and family values.

Mexican social customs when family or friends are ill and/or hospitalized include visiting, prayer, and fixing traditional foods and remedies. A priest and curandera are asked to visit. A party may be held in the hospital room. There is an effort to make the person feel loved. The whole family visits when a person is hospitalized.

Customs regarding death and dying include holding a vigil at home, novenas, and saying the rosary. Mass is held at a church, burial is in a close-by cemetery for dia de los muertos. There is an emphasis on continual closeness to the family. An anniversary mass is held for the deceased. Death is viewed as a positive experience that will bring people together with family and friends.

Key values guiding the behavior of the Puerto Rican cultural group are work, religion, respect, family, and love for their culture and language. Kissing and hugging are important behaviors in the Puerto Rican culture. One said: "that's the way we show affection and love."

Cleanliness is very important to Puerto Ricans. It is important to shower every day and wash hands before meals. They reported they usually eat their food first, and then get something to drink.

The most significant holidays/traditions of the Puerto Rican participants were New Year's Day; Christmas; Lent; and "Familia." Important Puerto Rican customs when family or friends are ill and/or hospitalized include providing support and visiting.

Puerto Rican customs regarding death and dying include remembering the deceased at every gathering and on special days, including fiesta, todasdo, santos, and Nuertos.

\section{Impressions of Class Differences.}

The Argentineans said they were not aware of class differences before coming to the United States. They noted they see class differences here based on money and education.

The Mexicans said they do not tend to categorize people by class. However, they said kinship and leadership status are very important. They usually refer to people by titles that indicate this status, for example: "tia, primo, comadre, and maestro." 


\section{Local Hispanic American Families}

\section{Family Roles and Decision-Making}

The Argentineans noted both the male and the female heads of the household are the key family decision makers, with the male being the main decider. In terms of gender roles and responsibilities, the man is seen as head of the house. However, couples work together in making decisions.

Key family decisions are made by the Dominican family as a whole or by the parents, or sometimes by an individual. The father or the parents usually make the final decision. Family reunions are an important time for family decision-making. Responsibilities are shared equally by both genders. Both genders are responsible for the welfare of children.

The Mexicans reported decisions are made by adults talking together and getting advice from grandparents and community leaders. Prayer is a part of the decision-making process. The grandmothers, then the mother, then the father are allowed to take part in decision-making. Parents/guardians are decision-makers, both the mother and the father.

Generally, Mexican women are the leaders in the home and in some social settings. Men are leaders in public positions. Often older women lead communities. Both Mexican men and women are equally expected to provide care to their children. When they both work, one at night and one during the day, they share responsibilities. The father is the one who provides discipline. The mother is the one who provides educational advice and medical/personal care.

The typical makeup of a Puerto Rican family is sometimes a single parent situation; but, on the whole, is the "same as the rest of the world." The extended Puerto Rican family is very important. One stated: "it doesn't matter how distant the relationship, they are familia." Key family decisions in the Puerto Rican culture are made by the head of the family. This may be the mother, father or maybe an uncle. The Puerto Ricans view their society as cooperative. They said: "Our elderly guide us in decisionmaking."

\section{Childbirth and Raising Children}

The Argentineans stated there are no particular beliefs or practices in their culture about pregnancy, childbirth, and circumcision. When raising children, the participants said it is important to explain the reason for disciplining. Disrespectful behavior in their culture would include not paying attention or "answering back."

Child-rearing is very important to the Dominican population. They said: "We spoil our children; they are our life.” The participants said they provide good examples and do not permit bad behavior. They said it is important to correct behavior and remind children if they act inappropriately. The participants said they "live for" their children. Having children is a planned goal; and pregnancies are planned. Pregnancy in marriage is good; pregnancy outside of marriage is not desirable, but the baby is welcomed. Circumcision is not practiced by this group.

The Mexicans characterized their child-rearing as guiding by quiet example. They said it is important to show children how to behave. They felt children should be made aware of community standards. The Mexicans stated bible-teaching is important. One Mexican said: "We raise our children through our community; all are responsible.” They felt discipline is important. Often, they said, the mother disciplines, but children listen more to the father. Talking; the use of time-outs; and hand slapping are disciplinary practices often used by young Mexican couples with their children. 
The Mexicans said respectful behavior in their culture entails listening to elders and learning from their experiences; considering the advice of elders; and helping elders. It is important in their culture to say "hello" and then "good bye." Children are taught to greet adults politely. Not looking at the eyes is a sign of respect, and having the head down is also respectful body language.

Disrespectful behavior in the Mexican culture involves causing people to lose their dignity and behaving arrogantly. Disobedience is a sign of lack of respect. "Talking back" to elders or any authority figure is disrespectful.

Puerto Rican child-rearing/disciplinary practices included watching over children carefully and using "time out." Some Latin cultures approve of spanking a child. The Mexicans said U.S. laws govern some of their child-rearing practices.

The Puerto Ricans said in their culture it is important to demonstrate respect. Disrespectful behavior included looking at a person in an offensive way. They said it is important others acknowledge "our ways and language." They also said it is disrespectful for others to not count Mexican opinions and to "make decisions for us."

\section{Sexuality, Marriage, and Relationships}

The Argentineans said it is important to follow the sequence of becoming engaged, marrying, and then having children. They believed sexuality is based on the bible. A sexual relationship is between a man and woman. However, the participants said they "have nothing against such persons who share with own kind...sexuality is private.”

Living as a married couple is highly valued by the Dominican group. Sex before marriage is not condoned. Cohabitation without marriage is not accepted by the church.

The Mexicans said they speak modestly about pregnancy. They stated babies are welcomed and loved by all- men, women and children. The Mexicans said circumcision is not practiced in their culture. Children are viewed as a gift from God.

One Mexican belief is if it is raining when the mother is pregnant, harm can come to the baby. The mother-to-be is encouraged to stay inside. This caused one of the participants to be fearful during her pregnancy. The Mexican participants said pregnancy is respected if the couple is married.

In the Mexican culture couples may live together first, with the approval of the family and community, if they are committed to each other and marriage is planned for a later time. Promiscuity is frowned upon. Homosexuality is not approved, but homosexual individuals are treated with dignity.

The Mexicans said they live for their children. They want to obtain the blessings of the church through marriage. One said: "Marriage must be between a man and a woman, not two men or two women." Courtship is practiced among young Hispanic couples. Cohabitation is not permitted if the person is not married unless the person is living with family. Homosexuality is usually accepted and openly talked about by the Mexican Hispanic community.

To the Puerto Ricans, pregnancy is a blessing from god. The Puerto Rican participants said they believe in courtship. They stated, "When we marry we gain another family." In terms of sexuality, the Puerto Ricans said there are many taboos. One Puerto Rican said: "We believe in washing our clothes in our homes.” In other words, in the view of the Mexicans, sexuality is "nobody else's business." 


\section{Living Circumstances May Include Extended Family}

Depending on economic circumstances, an Argentinean family may live with its extended family until it is financially able to establish a separate household.

The typical makeup of the Dominican family is father, mother, and children. About $60 \%$ of the homes include both parents. Approximately 15-20\% of Dominican families have grandparents living in their homes, too. The extended family is viewed as being very important.

The typical makeup of the Mexican family may include 3 grandparents, the mother, the father, and perhaps 5 children. Sometimes the family consists of an unmarried couple who live and have children together. Sometimes the mother lives with the children while the father works in another state; in these situations the family gets together on weekends. Often the extended family members provide care for children and assistance in the Mexican household. Godparents (padrinos) are very important. The extended family often gathers for holidays.

\section{Leisure Time Activities, Socialization, and Community Involvement}

The participants said there is not much time for the Argentineans in Luzerne County to become members of local clubs or organizations. There are not specific times for them to get together as a group for leisure pursuits. One participant liked to go out into the country area to a lake or woods. The Argentinean participants did spend time with other Jehovah’s Witnesses (mostly Americans).

The Argentineans socialized with Jehovah's Witnesses who are Americans. For example, the female participant taught Spanish to an American while learning English from her.

Clubs and community organizations to which the Dominicans in Luzerne County belonged included church groups; sports clubs (especially baseball); religious fraternities (like St. Francis); and "Amas de Casa” (a club for women). Members of this group socialized predominantly with those who speak Spanish and with friends of their children. To them, church provides a way to socialize. At work they viewed themselves as socializing every day. Outside of work they socialize with Latinos only. One person said other than at work, socialization with non-Latinos did not occur.

Key Mexican organizations included the Catholic Youth Center and church. Activities organized through the church were important. Leisure-time activities included going to parks, having cookouts; participating in fiesta gatherings with food, music, and prayers; reading; doing homework with children; attending family gatherings; cooking; camping at state parks with family; and walking. The Mexicans stated they are friendly to all but tend to stay within their families and communities. They often do not feel welcomed by non-Hispanics. There is not much socializing with non-Hispanics.

The Puerto Rican participants said they are involved locally in Hispanic and religious organizations. Much of the Puerto Rican participants' leisure time is spent working and attending religious gatherings and fiestas. The Puerto Ricans reported little socialization with people outside of their cultural group

\section{Life in Luzerne County}

The Argentineans reported feeling very welcomed by their Luzerne County neighbors. A major strength of life in Luzerne County for them was they have work and can buy things easily. The hardest part for them was being away from family, the food, and their native language.

All of the Dominican participants said they have been welcomed by the natives of the area, but they did not elaborate on this. Strengths of life in Luzerne County to these participants included church and community organizations which provide outreach services; the church at St. Gabriel's; the fact work is better paid; the cost of living is better than elsewhere; they feel welcomed; and work is available nearby. 
Hardships in the area included a lack of work for women; absence of warmth from some local residents; limited schooling and work; and problems obtaining medical help. Two participants said they were often refused medical services here. The participants identified working at home as an important way for them to spend their time.

Two members of the Mexican group said they did not feel welcomed by the natives of this area. However, others stated they felt very welcomed. The Mexicans noted the following problems associated with living in this region: police harassment; presumption of undocumented (residency) status; stress in being away from family; not having a car; lack of bilingual community services (health services); inefficiency in transportation; and the lack of a youth center.

The Puerto Ricans said sometimes they felt welcomed by the natives of the area. They relied on family support and the Catholic Church to help them adapt to life in Luzerne County.

\section{Health Care in Luzerne County}

The participants said Argentineans in Luzerne County tend to go to free clinics for health care, and tend not to have health insurance. The participants typically preferred to use a clinic for any needed medical or psychological help. Their impression of the formal health system in Luzerne County was it is very expensive here. This was in contrast to their home country, where such services are free. They found waiting for treatment in emergency rooms here is long and expensive. One said his income tax return was used to pay medical bills.

The primary caregivers in the homes of the Argentineans are whoever is at home. The participants were not aware of any specific health problems unique to their population, nor were they familiar with any specific commonly used health remedies. They were also not aware of any common health practices of their population. The participants said that when family or friends are ill and/or hospitalized, it is a family affair. Several members of the family visit when a family member is hospitalized. The Argentinean participants said they would not accept blood transfusion, but would accept other types of treatment.

The members of the Dominican group believed individuals who are ill must be helped. The primary caregivers in the homes of the participants included both men and women. Common illnesses of members of the Dominican population include asthma, bronchitis, and common colds. Treatments typically used included herbs and home remedies (such as vapor on the chest and soup). Common health practices of this population included exercise and listening to parental advice.

Medical and/ or psychological help for the Dominicans was typically obtained from hospitals, psychiatrists; the medical community; and at St. Joseph's (a local health care facility). This group said they also used clinics, such as the Freeland Clinic and St. Gabriel's, for health care. One person said "we have not been successful with receiving health care." Another said "we are refused service; we do not have a family or children’s doctor.”

The participants said they often turn to Dominican medical sources because they are refused medical attention by others. A number of the participants said they did not have adequate access to the local health system. They said they are in dire need of more doctors, as they do not have anyone willing to treat them.

The Mexican participants said they often utilized free clinics to access health care. One said there are not many options and that they "go home to Texas for proper care." Women and mothers are the primary caregivers of health care in the Mexican homes. The Mexicans said the family often provides the necessary medical care. 
The Mexicans said they will sometimes ignore illness if possible. Common illnesses of the Mexican participants were work-related injuries, high blood pressure, and diabetes. They said herbal and folk remedies were sometimes used. They consult "curanderos" and medical personnel at times. When seeking physicians, they will sometimes get a second medical opinion.

The Mexicans said as a group they do not have satisfactory access to health care in this area. However, they did say they get good care at the clinics they attended. They said it is difficult for individuals with no social security number to get appropriate treatment. Another complaint was the language barrier, particularly in the area of mental health services. They said the local health care system is not accessible. One stated, "We pray to stay well" and "we are in the hands of God and depend on his guidance."

The Puerto Ricans said they are typically "very private about our sickness.” One common illness they face is diabetes. Natural remedies (curanderos, healers, and sabadores) are often used by the Puerto Ricans. Common health practices of members of the Puerto Ricans often depend on their income. The Puerto Rican participants said they seek medical help from a family doctor, pharmacist, or priest.

The Puerto Ricans reported they do not find the Luzerne county health system to be accessible. The Puerto Ricans reported they often use free health clinics and rural health services.

\section{Interviewer Summary -Hispanic Focus Group}

\section{Key Health Issues and Needs}

Based on conversations with persons of all four Latino groups (Mexicans, Puerto Ricans, Argentineans and Dominicans) the key health Hispanic issues and needs indicate a correlation between residency status (immigrants) and ability to access health care.

Persons with insurance coverage, permanent residency status, or citizenship indicated health care access and challenges similar to the majority of people in the county. They indicated the "usual" physical health problems. These included hypertension, heart disease, and diabetes.

Conversely, for many Hispanic individuals in Luzerne County, access to primary health care is challenging. This is due to a lack of insurance coverage, which is a problem faced by many. Clinics providing services free of cost are often utilized by this group. However, because of the hours during which these clinics operate, it is often difficult to access services due to not having "time off" from work. The emergency room is utilized when there seems to be no other alternative.

\section{Issues Needing Careful Attention from Health Care Professionals}

Health care professionals need to be aware missing or arriving late for an appointment is not an indication of lack of interest or responsibility. Rebuking clients may serve only to further isolate them. Evening clinics may more readily meet the needs of clients who do not have access to primary health care. Health education programs on topics identified by the targeted group would also be of assistance.

\section{Recommendations for Health Care Professionals:}

Health professionals must focus attention on patients and be able to communicate to the patient what the health care professional is observing. During the focus group interviews, interpreters were used. They used various examples to gain information. This alerted this researcher to the fact the first answer given is not necessarily "the answer", nor is it the complete answer. Therefore, this type of probing can be of great assistance during health care assessments. 
Most persons interviewed seemed more comfortable communicating in Spanish, even though some were able to speak English. This researcher was present for interviews conducted by interpreters of non-Latino background and persons of Latino background. The persons interviewed were definitely more engaged with interpreters of Latino background and even offered more examples. The interviews conducted by the interpreters lasted longer than interviews which were held without interpreters, indicating improved communication when interpreters were present. 


\section{Appendix F}

\section{The Jewish Culture and Health Care Experience in Northeastern Pennsylvania}

This is one of seven appendices to a report from a northeastern Pennsylvania study called "A Focus Group Study of Diverse Local Populations and Their Health Care Experiences in Northeastern Pennsylvania: Cross-Cultural Issues." The study was conducted with support from the Diversity Institute of College Misericordia and the Blue Ribbon Foundation of Blue Cross of Northeastern Pennsylvania. This particular report focuses on the findings from the Jewish focus group.

\section{Participants}

There were a total of 7 Jewish participants. These included 2 Russian Jews and 1 Lubavitch Jew. The ages of the Jewish participants were 30, 39, 40, 54, 61, and 67 years of age. There were 4 males and 3 females.

Participant income levels included 1 participant whose family income was under \$20,000; two participants with family incomes between $\$ 21,000-50,000$; two participants with family incomes greater than \$76,000; and two participants with "unknown” incomes. The employment status of the participants included: professional community volunteer, retiree, self-employed advertising marketer, financial advisor, retired home health nurse, psychologist, and clerical assistant

All of the participants attended college. Two earned graduate degrees. The number of years the participants resided in Luzerne County was: 5, 7, 20, 30, 53, 67 and 1 unknown. The number of years the participants resided in the United States was 30, 39, 40, 54, 61, 67, and 1 unknown.

Three of the participants had family members who immigrated to this area from Russia. Two came here for employment reasons.

\section{The Local Jewish Population}

\section{Size and Economics}

The participants thought there are about 3,000 Jews in Luzerne County. Most reside in Kingston and Dallas. The majority responded the family income of the Jewish population in Luzerne County is about $\$ 40,000$ and up. One participant did state the range could be as low as $\$ 20,000$.

\section{Employment Trends}

The most common employment in the local Jewish community is in professional positions. There are many Jewish doctors, lawyers, and teachers in this region. Business workers, receptionists, and factory workers are other jobs in which the local Jewish population is found. It is not uncommon to find both parents working outside the home.

\section{English versus Hebrew and Yiddish}

Hebrew and Yiddish are the two languages identified as "home languages." English is used most of the time.

\section{Religious Practices}

The major Jewish religious sects in the community are Reform, Conservative and Orthodox. The primary religious holidays observed are Rosh Hashanah, Yom Kippur, Pesach (Passover), Shavuot, and the Sabbath. Acceptable dress may include long skirts and long sleeved blouses for Orthodox females. Orthodox men may often wear black hats and other conservative garb. 


\section{Value System}

There are 613 commandments in the Torah. (The Torah consists of the first 5 books of the Hebrew bible. The Hebrew bible is what Christians call the Old Testament. Jewish people do not use the terms A.C. and B.C. when referring to dates in time. Instead, they use the term BCE- "before common era", and ACE"after common era.") Many Jews are familiar with "The Ten Commandments.” Key values of this ethnic group include honesty, morality and integrity. Charity and community service are important within the Jewish community. Jews are taught they can make the world a better place, and they can and do make a difference on earth. Jews are also taught to respect the sanctity of life. Saving the mother over the fetus in times of crisis is expected. Jewish people want others to be upfront with them and not "beat around the bush.”

Respectful behavior is shown by honoring the separation of men and women (in touching) among observant Jews. Reaching out to those in need in the community and giving back to the community are also important. Following the "Golden Rule" and using good manners are also stressed. Examples of disrespectful behavior are forcing an observant Jew to eat non-Kosher foods (pork, shellfish, etc); religious intolerance; gossiping; ignorance of Jewish laws; and acting "holier then thou."

All participants agreed the local Jewish population tends to categorize people by economics, religion, and living location. However, there was some mention this is done less in Luzerne County than in other areas.

\section{Customs and Traditions}

\section{Touching}

Jews are very affectionate within their own group. However, men and women do not openly touch one another unless already married. Within the Orthodox sect women are only allowed to touch men -when it is prescribed by Jewish law. In times of medical need, touching is permitted.

\section{Cleansing Rituals}

Cleanliness is an important custom in the daily lives of the Jewish population. Washing one's hands before meals, and also when returning from a cemetery, are customs and in some homes rituals. There is a special cleansing ritual used for the deceased before they are buried. A new Mikvah is being built in Kingston. A mikvah is a place for ritual bathing. Mikvahs are used regularly by some Jews in the community. Before a couple is married they cleanse in a mikvah and Orthodox women cleanse in a mikvah at certain times of the month.

\section{Meal Traditions and Practices}

Traditionally, Jewish food is high in cholesterol, carbohydrates and fat. Many holidays and celebrations in Judaism are centered on food.

Many Jews fast for certain holidays. No bread is permitted for Passover. Many Jewish people keep kosher. This entails not mixing meat and dairy, only eating kosher meat, and not eating shellfish, pork, or foods and beverages not processed in a specific manner. On Friday night (the Sabbath) Jewish families typically come together for a special meal. The family celebrates the Sabbath dinner as a meaningful and spiritual time.

\section{Traditions Related to Sickness and Dying}

Visiting the sick is a mitzvah (a good deed)- a Jewish commandment. It is expected for family, friends and acquaintances to visit the ill at home or in the hospital. Sometimes up to 10 Jews will visit at one time for ritualistic purposes. 
The deceased's body goes through a special ritualistic cleansing and is watched by another Jew until buried. Traditionally, the body is buried within a 24 hour period, unless it falls on the Sabbath or specific holidays. Friends and family members gather at the family's home to sit Shiva. They are a support for the family during their time of sorrow. Often all the mirrors in the home are covered for a period of time so the mourners may focus on grieving and not on their appearance.

\section{The Jewish Family}

\section{Family Make-Up, Gender Roles, and Decision-Making}

The majority of local Jewish families consist of two-parent homes. However, there are some single parent homes. In some Jewish families, extended family members live nearby. Though it has been a tradition for families to live near one another in the past, this is changing. Extended families are extremely important to the Jewish people. The celebration of many of the holidays and life cycle events are to be shared with family members. The family unit is a major resource for child care, self-help support, senior care, and times of illness.

Orthodox Jews uphold traditional roles for each gender. In the Orthodox synagogue the men and women worship separately. Orthodox Jewish women typically take care of the family and the home while the men study, work outside the home for pay, and defend their country. In the Conservative movement the roles are more split. The Reform movement is more egalitarian and men and women have more shared roles.

In the traditional Conservative and Orthodox home, the woman runs the home and her husband is responsible for overseeing many of the decisions. In the Reform sect, the decision making process is jointly done by the adults in the home and the family.

\section{Child-Rearing}

Many times throughout history the Jewish population was persecuted, victimized, and even killed. For this reason many Jewish people believe larger families are needed to repopulate the Jewish community. Pregnancy in the Jewish population is considered to be a gift, requirement, and a miracle.

In Orthodox Judaism, and according to Jewish law, items for newborn babies are not allowed to be purchased or brought into the home until the birth of the baby. Circumcision (Bris) is performed on the eighth day after birth. This is usually done by a medical doctor or a Moyel (ritual circumciser). Breast feeding is not accepted in public places. The life of the mother is saved over the fetus if one has to choose.

Children raised in a Jewish home are taught to love and respect their families. Parents can be lenient or strict. Typically those who belong to the Orthodox sect have larger families and are not as strict. Judaism stresses children are the world's hope for the next generation. Common Jewish disciplinary strategies are 'time outs," having something taken away, or "being grounded."

\section{Courtship and Marriage}

In the Jewish culture courtship is important. Depending on the sect of Judaism, views regarding cohabitation and homosexuality differ. In the Conservative and Orthodox sects interfaith marriages are not accepted; homosexuality is considered unfortunate; and cohabitation is not an option. The Reform Jewish movement is more open to interfaith marriages, accepting of homosexuality, and more tolerant of men and woman living together without marriage. In all of the Jewish sects the child takes on the Mother's religion. 


\section{Community Involvement}

In 1845 the gentile community supported and helped a local Jewish community build a Reform Synagogue. Overall, the Jews of Luzerne County feel welcomed in the area. However, those who are more willing to participate in the community tend to feel more welcomed than those who do not. A common stressor found among the participants was when you are new to the area it is difficult to meet people. Not knowing someone in the area was considered a major stressor. It was said that a strength of the area is the natives will guide you if you are willing to follow.

\section{Socialization, Leisure Activities, and Community Organizations}

The Jewish focus group participants reported frequent interaction with non-Jewish members in this community. Only one participant socialized exclusively with those of the Jewish Community. Part of this was due to dietary laws.

Several of the most common leisure time activities for the local Jewish population are Maj Jong, playing cards, volunteering, being with family, walking, golf, tennis, cooking, and reading.

Members of the area's Jewish community are involved in many different organizations. However, they usually are involved with the synagogue of their choice and the Jewish Community Center. B'nai B'rith Men's Lodge, Jewish War Veterans, Jewish Federation, Jewish Family Service, and the United Hebrew Institute are organizations to which many Jews volunteer time or sit on boards. Non-sectarian organizations which Jews in the community belong to include the United Way and YMCA.

\section{Health Beliefs and Practices}

The Jewish participants believed a healthy diet and regular exercise are important in maintaining a balanced lifestyle. Physical health is very important in this culture. They said "The Torah teaches we are to take care of our bodies. We are not to mar them or do anything which will result in deep physical pain or psychological damage.” Common illnesses among Jews are Tay-Sachs disease, diabetes, heart disease, gastro-intestinal disturbances, and Krohn’s Disease.

Mental health illness in the Jewish culture was not accepted or acknowledged in the past as it is today. Many feel there is more drug abuse than alcoholism in this culture. The Jewish participants felt mental illness should be treated along with physical illness. Jewish individuals often seek treatment from massage therapists, physicians, and psychologists.

Important health practices of this group are cleanliness (including frequent hand-washing), regular checkups, and listening to physician recommendations. Unfortunately, many Jewish traditional foods were found to be unhealthy for those watching their diets. Checking that a food is kosher is also a common practice for those who observe kosher dietary rules.

\section{Health Care Providers}

For many medical problems, Jewish members of the community typically go to board certified physicians they know or who have been recommended by other Jews. Jewish doctors are preferred due to the fact they better understand the needs of Jews. However, if there seems to be a serious health issue, Jewish residents of this region tend to seek services outside of the local area. The caregiver in the Jewish home is usually the mother; however, today it is not uncommon for the father to be considered the caregiver.

\section{Access to Health Services}

The Jewish participants felt the health care system in Luzerne County overall is good. Much depends on the type of health care coverage a person has. If an individual or family does not have good health insurance, they are more limited in services. Unfortunately, the participants noted there are not as many 
young physicians left in the community. Many of the doctors (who were friends of those in the local Jewish community) left the area because they were unable to get affordable malpractice insurance.

Another issue several of the participants touched on was they do feel it is more difficult to get to know your caregiver. They also feel the doctor does not get to know patients or families as they did in the past. The participants felt the difficulty in getting care at times stems from the influence HMO's have on medical care.

\section{Interviewer Summary- Jewish Focus Group}

In the Jewish focus group, the overall issue regarding health care was the patient /physician relationship. For the most part, all the participants in one way or another commented the doctor no longer has the opportunity or interest in learning about the patient and his/her whole family. The family is very important in the Jewish population. Having an understanding of the family can help in treating and working with the patient.

Diet is a very important issue for this population. Many of the traditional foods are high in sodium, cholesterol, fat, and carbohydrates. Luzerne County has a high population of Jewish senior citizens. It is difficult for them to consider changing their eating habits.

Health care professionals need to recognize the importance of the family when treating a patient. They also need to have a better understanding of Jewish dietary laws. In many cases health care providers are not aware of the Jewish holidays and the foods associated with them. An example of this is Passover. It is at this time nothing leavened may be consumed. For example, it is not appropriate at that time for a healthcare provider to tell a Jewish patient to eat a piece of toast to help sooth an upset stomach.

Like other populations, the Jews do not like to feel they are unimportant. If a Jewish person feels the need to be seen by a physician they want to be seen within that week- not a month or two from then. The focus group interviews showed a significant number of elderly Jews in Luzerne County feel their health care providers perceive them as hypochondriacs. Whether they are or not they want to be seen and their appointments should not be put off to a much later date.

The Jewish focus group leader said health care professionals who are not Jewish need to be aware many Jewish senior citizens may have highly assertive, and even aggressive, personalities when it comes to their health care. Often they will not hesitate to question what the health care provider may be telling them. They also want to be informed and have a good understanding of their condition. 


\section{Appendix G}

The Asian Indian American Culture and Health Care Experience in Northeastern Pennsylvania

This is one of seven appendices to a report from a northeastern Pennsylvania study called "A Focus Group Study of Diverse Local Populations and Their Health Care Experiences in Northeastern Pennsylvania: Cross-Cultural Issues." The study was conducted with support from the Diversity Institute of College Misericordia and the Blue Ribbon Foundation of Blue Cross of Northeastern Pennsylvania. This particular report focuses on the findings from the Asian Indian American focus group.

\section{Participants}

There were 8 participants in the Asian Indian American focus group. These included 4 males and 4 females. The ages of the four females were 24, 30, 37, and 65 years old. The ages of the four males were 29, 35, 55, and 67 years old.

One participant reported a family income in the $\$ 21,000-\$ 50,000$ per year bracket. Two participants reported family incomes in the $\$ 51,000-\$ 75,000$ per year bracket. Five participants reported family incomes over $\$ 76,000$. There were 3 physicians, 1 professor/researcher, 1 research chemist, 1 assistant vice president of finance, 1 system analyst, and 1 health professional in this participant group. The highest educational level achieved by the participants included five doctoral degrees, two master's degrees, and one bachelor's degree.

The number of years which the 8 participants lived in the Luzerne/Lackawanna County area was 2, 3, 6 , $8,12,20,20$, and 34 . The number of years which they lived in the U.S.A. was 3, 8, 10, 12, 29, 30, 38, and 40 .

The Asian Indian American participants in the focus groups came to the United States either from the Indian subcontinent or from other parts of the United States. They came to the area to pursue higher education or business/job opportunities. They were attracted to the region by the lower cost of living, low crime rate, and quiet peaceful life of a small town; the relative ease in finding positions due to the shortage of professional people (i.e., physicians, engineers, teaching faculty), and the opportunity for success.

\section{The Local Asian Indian American Population}

\section{Population Size and Income Level}

The focus group participants estimated the Asian Indian American (AIA) population in this area is small (between 400 and 1200). They reported some families live in Scranton and Wilkes-Barre. However, most AIAs settled in the suburbs of Clarks Summit, Peckville, Mountain Top, and Laflin. The family income of this group was estimated to be between $\$ 30,000$ and $\$ 75,000$ for single income families, and above $\$ 75,000$ for dual income families.

\section{Employment: Many Highly Educated Professionals.}

There is a large concentration of Asian Indian American physicians in the northeastern Pennsylvania region, and most of them are men. Many others are educated professionals (such as college professors, engineers, computer professionals), self-employed (for example, in real estate), or work in factories. Most respondents indicated both husband and wife work outside of the home. It was noted more women are employed outside of the home in the United States than in India. 


\section{Key Values}

The participants said the priorities of most AIAs are to secure the future of their children and provide financial support for their parents. Other key values mentioned include respect for elders, family honor, discipline, hard work, education, loyalty, truthfulness, putting others before oneself, secularism and religious tolerance.

Although two individuals responded the AIAs do categorize people by class, the other six felt they did not. One commented AIAs categorize first by region of Indian origin (the language they speak), second by profession/level of education, and third by income.

\section{Cultural and Religious Practices}

\section{Language}

The home languages spoken by the 8 participants include Gujarati, Punjabi, Hindi, Bengali, Telugu, Malayalam, Marathi, and Kannada. All participants indicated that a "home language" other than English is spoken in their social and/or family environment. The importance of the use of English in assimilating with society was mentioned as well as the fact U.S.-born children prefer English. However, most agreed language preservation is paramount to their households because the mother tongue is the cornerstone of their cultural identity.

\section{Holidays and Religious Occasions}

Although Christianity, Islam and Sikhism were mentioned as religions practiced by individuals in this group, all participants reported being of the Hindu faith. The most significant holidays noted were:

- Holi - This is a Festival of Colors celebrated on the day of the full moon in early March.

- Diwali (Deepawaali) - This is a Festival of Lights symbolizing the victory of good over evil and the glory of the light. It is celebrated 20 days after Dussehra, on the 13th day of the dark fortnight of the month of Ashwin (October/November). This festival resembles Christmas. It is a time of holiday feasting and family visits. Hindus spend the day visiting friends and family and exchanging gifts and sweets.

- Dassera - This is celebrated in the Hindu month of Ashwin which falls in September/October. It marks the end of Navratri, the festival of nine nights. It is a time of holiday feasting and family visits. Many Indo-American Cultural Societies organize "garba" or "dandia" dances here in the U.S. in Hindu temples and/or homes.

- $\quad$ August 15th - This is India's Independence Day.

- Ugadi (New Year) - This holiday marks the beginning of a new Hindu lunar calendar with a change in the moon's orbit. It is a day when mantras are chanted and predictions made for the New Year.

- Clothing.

Most people of Asian Indian origin dress in western style on a day-to-day basis, but in Indian clothing for religious and social gatherings. Women's traditional Indian clothing includes the sari and salwar-kameez. The sari is a rectangular piece of cloth five to six yards in length which can be worn in many ways. The slawar is a pajama-like trouser drawn tightly at the waist and the ankles. A kameez, a long and loose dress, is worn over the salwar. Men's traditional clothing includes the kurta and dhothi. The dhoti is a long length of material worn around the thighs like a sarong with an additional length of material pulled up between the legs. The kurta is a knee length collarless shirt adorned in white or pastel colors. 


\section{Customs and Traditions}

\section{Dietary Practices}

The participants reported there is a generally a high level of awareness about correct dietary and nutrition needs of the family. A large percentage of AIAs are vegetarians. The participants commented they find it difficult to get the correct nutrition, especially when eating out.

Fresh cooked and home cooked meals are preferred. Traditional Indian food consists of breads, curries, and other dishes made of wheat, rice, vegetables, spices, milk and milk products. Somewhat spicier food is preferred. It was noted the main reason for avoiding beef is the dairy products from cow's milk are more valuable - "the cow is worth more live than dead." Fasting (a form of self-control and sacrifice) once a week or once a month, based on religious occasion, is somewhat common.

No specific meal-time rules were reported. Although desserts are served with the main meal in a traditional Indian setting, it was noted this trend is changing. Also, traditionally, women eat after men, but in the U.S. Indians try to eat as a family with children and adults at the same time. Many eat with their hands, in the traditional Indian way. Dinners are usually later in the evening. AIAs pray before eating for blessings and generally do not drink water until the end of the meal.

Traditional Hindu custom calls for strict personal and social hygiene. Many AIAs do not have breakfast before showering. Hand washing before cooking and before and after eating is very important.

Generally, AIAs remove shoes before entering the house. Shoes are never worn where cooking or prayers are taking place.

\section{Touching and the Importance of Physical Distance}

Physical distance is usually maintained at a respectable and comfortable level between most community members. Kissing (on the cheek) and hugging are uncommon even among good friends. Even husbands and wives rarely express physical affection in public. However, male friends and especially female friends will hold hands without being considered homosexual. Elders pat their children's heads or backs as a sign of blessing.

\section{Sickness, Death, and Dying}

All participants noted they do visit ill or hospitalized family and friends often and provide moral support or offer to pray with the family of the patient. Some people may cook for the sick person's family. Flowers and cards are usually not traditionally part of the visit, but AIAs do send practical gifts like food and fruits.

Dying people are taken care of by their families as much as possible. Many believe 'seva', or serving others, will benefit them too. Extended families and friends join in the mourning and grieving after death. Cremation is common. Burial is rare. Rituals traditionally last up to the sixteenth day after the cremation.

\section{The Family}

\section{Family Make-up and Decision-Making}

The typical makeup of the family in this country is father, mother, and children, but if the grandparents are in the United States, they often all live together. Since divorce is rare, there is a lower incidence of single parenthood.

Most respondents indicated the extended family is very important. To them, the "family" is the "extended family.” However, two individuals noted it is not as important to them in the U.S. 
Family decisions are made for the good of the entire family. Generally everyone (including children) expresses opinions. Then the parents ultimately decide. If the husband and wife cannot agree, the husband makes the final decision in most Indian households.

\section{Gender Roles and Responsibilities}

In the traditional Asian Indian family males are the "bread-winners." Males take care of money matters and heavy work. Females are responsible for household matters, such as cooking, chores, rearing of children, and religious activities. However, women currently assume greater responsibilities and roles outside of the home.

\section{Beliefs about Marriage and Sexuality}

The participants reported most courtships are brief- whether or not to marry is decided early. Marriage is viewed as being very sacred. Cohabitation with a member of the opposite sex outside of marriage, having children outside of marriage, bisexuality, Tran sexuality, homosexuality, and living single are considered socially taboo in India. Most Indians living in the US brought those beliefs with them. However, the trend is towards more tolerance on this topic.

\section{Pregnancy, Childbirth, and Circumcision}

Pregnancy is considered a special time. Pregnant women are careful about nutrition and decrease strenuous activity at this time. Special prayers are done for pregnant women in the sixth and ninth month. Prayers are also made for a woman to get pregnant if after repeated attempts she does not become pregnant. Childbirth is very private and is considered the next step after marriage. Most men are not circumcised unless medically required.

\section{Child-Rearing and Disciplinary Practices}

Child rearing is very important. Children are well cared for and at the same time well disciplined. Most AIAs are rather strict with their children in instilling traditional Indian values and the need to excel. Restricting privileges and time outs are common. Physical punishment is not unheard of, although discipline is generally done in a very positive way. Children are rewarded for doing well- usually through words and favorable gifts.

\section{Respectful Behavior versus Disrespectful Behavior}

Respectful behavior is shown by listening to elders, asking their opinions in important matters, and touching their feet. AIAs welcome people with folded hands and bow their heads slightly upon greeting. When leaving they say goodbye to all. The language includes words which imply respect when referring to people.

Staring, making direct eye contact, and not acknowledging someone, are considered "disrespectful behavior." Drinking alcohol, smoking, and sitting when elders enter a room (instead of standing up and waiting to be seated when told) are considered disrespectful behaviors.

\section{Leisure Activities and Community Involvement}

\section{Leisure-Time Activities}

The leisure-time activities of the participants were diverse. They include reading, socializing with the Indian community, spending time with family and friends, and having dinner at each other's homes. They also like traveling, outings, movies, and music and games. 


\section{Socialization}

When asked if they socialized with people who are not of Asian Indian origin, participant responses varied from "not much" to "a very great extent." One individual noted some AIAs may not be comfortable socializing with non-group members because of trepidation due to language barriers and cultural differences. The similarities of AIAs make it easier for group members to stay together, leaving little time for non-group interaction.

\section{Clubs and Community Organizations}

AIAs participate in a variety of local, regional, and national organizations. They include the IndoAmerican Association of Northeastern Pennsylvania, Hindu Cultural Society of New York, American Association of Physicians of Hindu Origin, Chamber of Commerce, Lackawanna County Medical Society, Pennsylvania Medical Society, YMCA, PTA, and other professional or social organizations.

\section{Life in Luzerne/Lackawanna County}

The participants were split on their view of how they were received here. One individual remarked the "natives" may appear to be uninviting, but he doubted it stems from overt racism. Another said AIAs are seen by some as immigrants taking away jobs from the natives. Others said AIAs are accepted by the natives and acknowledged as being good people. One noted most of the natives are nice, but observed some do not like change and are thus reserved until they know AIAs better.

Economic pressures, language barriers and cultural differences were identified as the stressors of living in the area. The eagerness among Indians to be 'accepted', their education and income, and the cosmopolitan nature of the county were seen as major strengths.

\section{Health and Medical Care}

The participants reported AIAs go to primary physicians and specialists and local hospitals and clinics for health care. One individual pointed out AIAs go to a doctor only if they are sick.

Keeping in good physical and emotional health is important. Physical fitness is growing in popularity. All illnesses need to be treated, although mental illnesses may sometimes be neglected by AIAs.

Diabetes, heart disease, hypertension, ulcers, low HDL syndrome, mild obesity, and skin disease were identified as being very common in AIAs.

Several individuals noted traditional herbal remedies are commonly tried before going to a doctor. Home remedies and "natural" or food/diet changes and herbs were also identified as being used to treat illnesses like degenerative joint disease.

Although AIAs turn to medical doctors for physical illnesses, psychological help usually takes the form of family and Indian community support. People with disabilities are cared for in the home environment and not usually institutionalized.

Not all AIAs perceive allopathic medicine to be perfect. Traditional herbal medicine/homeopathy may be sought by many. Certain religions have religious beliefs and prayers. Drinking water with meals, a truly varied diet (vegetarian), exercise, very little drinking (alcohol), and not smoking were also identified as common health practices.

Grandparents and women (regardless of their working status) were identified as the primary caregivers in the homes. 
All of the focus group participants said primary health care in the region is accessible. However, specialized care was noted as being deficient.

\section{Interviewer Summary}

\section{Asian Indian American Focus Group}

As a group, most of the participants reported they have insurance coverage. They said they seek medical help after trying out home remedies (grandma's medicine!). They generally believe in traditional allopathic medical practice. The group as a whole did not hesitate to seek help from professional doctors and therapists. Alternative medical help was not sought by the Asian Indian Americans due to limited availability and not having enough trust in the alternate medical practitioners.

The participants said most young Asian Indian American adults are relatively healthy. Usually it is the older adults who need medical attention. Hypertension, coronary artery diseases, and diabetes are some of the most common conditions needing medical attention by this population. The participants reported they usually follow medical advice as prescribed and have good follow through on medical recommendations.

When treating an Asian Indian American, health care professionals may communicate with several family members. The participants indicated it may be helpful to designate one family member as the primary spokesperson and communicate all information through that person. They said typically the primary spokesperson should be the male head of the family. For health care issues involving children, they felt it is best to convey most of the information to the mother, as typically she is the one who handles children's health issues. 